\title{
The Role of Customer Investor Involvement in Crowdfunding Success
}

\author{
Philipp B. Cornelius, ${ }^{\text {a }}$ Bilal Gokpinarb \\ ${ }^{\mathbf{a}}$ Rotterdam School of Management, Erasmus University Rotterdam, 3062 PA Rotterdam, Netherlands; ${ }^{\mathbf{b}}$ UCL School of Management, \\ University College London, E14 5AB London, United Kingdom \\ Contact: cornelius@rsm.nl, (D) http://orcid.org/0000-0003-4286-8556 (PBC); b.gokpinar@ucl.ac.uk, \\ (iD) http://orcid.org/0000-0001-9299-2876 (BG)
}

Received: May 31, 2014

Revised: March 11, 2015; July 6, 2016;

March 27, 2017; May 22, 2018;

September 6, 2018

Accepted: September 10, 2018

Published Online in Articles in Advance:

May 31, 2019

https://doi.org/10.1287/mnsc.2018.3211

Copyright: (c) 2019 The Author(s)

\begin{abstract}
Entrepreneurs increasingly use reward-based crowdfunding to finance innovation projects through a large number of customer investments. The existing academic literature has predominantly studied factors that drive crowd investments and whether crowdfunding predicts market success. However, we argue that the involvement of customers goes beyond the provision of capital. As investors, customers enter into a principalagent relationship with entrepreneurs. Thus, entrepreneurs are often faced with a crowd of customer investors who try to influence product development. We show that entrepreneurs can benefit from this influence, because customer investors provide some of the support usually received from institutional investors. Greater involvement from customer investors thus increases funding success. This holds when we control for creator ability and project quality. The effect is driven by customers' influence on product development and the reduction in agency costs for prospective customers. We also link the involvement of customer investors during crowdfunding to the crowdsourcing literature and show that its positive effect is augmented by the elicitation of external information through distant search.

History: Accepted by Lee Fleming, entrepreneurship and innovation.

Open Access Statement: This work is licensed under a Creative Commons Attribution-NonCommercial-

NoDerivatives 4.0 International License. You are free to download this work and share with others, but cannot change in any way or use commercially without permission, and you must attribute this work as "Management Science. Copyright ( 2019 The Author(s). https://doi.org/10.1287/mnsc.2018.3211, used under a Creative Commons Attribution License: https://creativecommons.org/licenses/bync-nd/4.0/."

Supplemental Material: The online appendices are available at https://doi.org/10.1287/mnsc.2018.3211.
\end{abstract}

Keywords: crowdfunding $\cdot$ new product development $•$ crowdsourcing $\cdot$ entrepreneurship $\bullet$ principal-agent relationship

\section{Introduction}

Funding innovation through direct customer investments is a key benefit of reward-based crowdfunding (Younkin and Kashkooli 2016). ${ }^{1}$ The growing literature on crowdfunding has predominantly studied the exchange of financial resources between backers and project creators (Kuppuswamy and Bayus 2018), examining backers' contribution patterns (Burtch et al. 2013, Mollick 2014, Agrawal et al. 2015, Burtch et al. 2015, Lin and Viswanathan 2016) and the rationality of crowd investments (Mollick and Nanda 2016). However, the involvement of customers in reward-based crowdfunding projects goes beyond the provision of financial resources. Customers also use crowdfunding platforms to share ideas and suggestions for the products they fund. From the project creators' perspective, crowdfunding can thus be considered a distinct form of crowd-based knowledge sourcing (Bayus 2013, Dahlander and Piezunka 2014, Piezunka and Dahlander 2015), in which members of the crowd both fund and influence the development of a product.
Customers' financial stake in crowdfunding projects has an important implication. Like conventional investments in start-ups (such as by venture capital funds), customers' investments in crowdfunding projects create a principal-agent relationship between customers and project creators (cf. Jensen and Meckling 1976). As principals in this relationship, customers depend on project creators to develop a product that maximises their utility (Nambisan 2002). Customer investors are thus particularly incentivised to monitor project progress and influence product development to limit divergence from their optimal product (Nambisan 2002, Agrawal et al. 2014). Therefore, when entrepreneurs seek investments through reward-based crowdfunding, they often face strong influence from a crowd of customer investors.

The objective of project creators is to create products that can successfully raise funding. On the one hand, involving customers in product development can help create better products (von Hippel 1994, Lilien et al. 2002). On the other hand, the principal role of customers 
may also impede product development. A crowd of dominant customer investors with strong influence on the project can subject project creators to the perils of group irrationalities (Isenberg 2012). The loss of strategic autonomy to dominant customers is a key concern for innovating entrepreneurs (Fischer and Reuber 2004). Indeed, it is well documented that "customers' short-term and current experience bias" (Wind and Mahajan 1997, p. 6) and their lack of technical knowledge (Magnusson 2009) can steer projects into competitively undesirable technologies (Nijssen et al. 2012) or niche products (Ramdas et al. 2007).

Thus, an important first question is whether project creators can benefit from the involvement of customer investors or whether increasing influence from the crowd decreases funding success. We argue that customer investors assume some of the value-adding activities usually carried out by institutional investors (Bottazzi et al. 2008). Customer investors gather information about the project, monitor project progress, and influence product development. These activities affect funding in two ways: by mitigating agency issues for new customers and bringing a balanced "voice of the customer" into product development (Griffin and Hauser 1993). As a result, projects with greater customer involvement raise more money from crowdfunding than projects with less customer involvement. We show that this positive effect of customer involvement on funding is stronger for projects run by individuals, which rely more on reducing agency costs through customer involvement.

But do customer investors really influence product development, and do changes to product specifications in response to customer input increase funding success? This is the second research question we address in this study. Building on the product development literature, we argue that customer investors share "sticky" information about their desired product applications (von Hippel 1998). At the same time, customers' investment in projects aligns their incentives more closely with those of the creators, so that customers are less likely to ask for costly niche products (e.g., Ramdas et al. 2007). The result is a more feasible set of customer suggestions, which allows project creators to identify opportunities and adapt their products to a wider range of customers. The effect of customer input on funding success is thus partly mediated by the extent to which project creators change product specifications in response to customer input.

Finally, we link the involvement of customer investors in crowdfunding projects to the crowdsourcing literature. By interacting with customer investors, crowdfunding project creators elicit external information-such as suggestions for new markets or product applications. The elicitation of information from external "problem solvers" is also the underlying mechanism of crowdsourcing (Jeppesen and Lakhani 2010). A main advantage of crowdsourcing derives from the transformation of distant search into local search through the elicitation of distant information from external problem solvers (Afuah and Tucci 2012). Does the involvement of customer investors with distant investment experience also improve the performance of crowdfunding projects? This is the third and last question we seek to answer in this paper. We argue that this is indeed the case, as customer investors' shared role as problem owners and problem solvers facilitates the appropriation of distant knowledge in complex problems. Furthermore, the exchange of knowledge in crowdfunding pertains largely to the application of a given product. Hence, the involvement of customers with investment experience in distant domains of application (e.g., theatre and video games) increases funding success.

We study the involvement of customer investors in crowdfunding projects in a unique data set comprising 21,491 projects from a diverse set of entrepreneurs and industries. Unlike most of the previous innovation literature, which uses data on successful innovations such as granted patents (e.g., Singh and Fleming 2010, Chatterji and Fabrizio 2011; for a discussion of patent data, see Fontana et al. 2013, Hall et al. 2013), prescreened innovation projects (e.g., Lilien et al. 2002, Bajaj et al. 2004), or management questionnaires (e.g., Gruner and Homburg 2000, Foss et al. 2010), our data comprise a balanced set of successful and unsuccessful projects, thus reducing selection bias (Dahlander and Piezunka 2014). The detailed data also allow us to granularly observe actual instead of perceived customer input and to employ a range of control variables, such as creator preparedness and crowdfunding experience.

An important empirical issue in many innovation studies is the endogeneity of project quality. In this setting, for instance, project quality may increase both performance and customer investor involvement: Good projects may attract more funding, and customers may be more motivated to support such projects. We address this issue by using the introduction of a mobile app as an instrumental variable (IV) for customer involvement, thereby controlling for project and team quality (we discuss the instrumental variable in more detail in Section 4.1, and we discuss its limitations in Section 6). Another important empirical issue in crowd settings is social learning, as customers' funding decisions may be influenced by the sheer presence of other customers (Zhang and Liu 2012, Burtch et al. 2013, Kuppuswamy and Bayus 2017). We address this issue with an additional set of panel models that explicitly control for social learning.

The results of the empirical analysis confirm the hypotheses. Customer input increases funding success, in particular for individual project creators and if customers with distant funding experience provide input. Importantly, the effect of input on funding success is partly mediated by whether creators adapt project descriptions in response to customer input. 
This paper provides important contributions to the crowdfunding and crowd-based knowledge-sourcing literatures. The exchange of nonfinancial resources, such as knowledge, human labour, and social capital, has received little attention in the existing crowdfunding literature (Fleming and Sorenson 2016, Kuppuswamy and Bayus 2018). Departing from the emphasis on the financial exchange mechanism, we investigate the broader role of customer investors during crowdfunding. We advance the idea of a principal-agent relationship between customer investors and project creators and show that project creators can benefit from the involvement of customer investors. The mechanism resembles the elicitation of solutions in crowdsourcing (Afuah and Tucci 2012). Crowdfunding may therefore be considered a distinct form of "crowd-based knowledge sourcing" (Piezunka and Dahlander 2015), which combines the elicitation of solutions with their funding. The study also has implications for the entrepreneurship literature, as we show that crowds of customer investors can, at least in part, substitute for the value-adding activities usually performed by conventional angel investors or venture capitalists (Fischer and Reuber 2004, Bottazzi et al. 2008, Ley and Weaven 2011).

We develop the hypotheses in the next section, describe the setting and data in Section 3, analyse the instrumental variable models in Section 4 and the panel models in Section 5, and discuss results, limitations, and avenues for future research in Section 6.

\section{Hypothesis Development}

Crowdfunding allows entrepreneurs to "raise capital from many people through online platforms" (Agrawal et al. 2014, p. 63). To finance product innovation projects, entrepreneurs can use reward-based crowdfunding to raise funds through product presales (Fleming and Sorenson 2016, Kuppuswamy and Bayus 2018). Once entrepreneurs have a prototype of their product, they can create a public, reward-based crowdfunding campaign in which they describe the product and their development plans. After the campaign is launched and before a set end date, customers have the opportunity to purchase the product (called the "reward"). With the money raised, the entrepreneur finishes product development, produces the product, and delivers it to the customers.

A key difference from traditional consumer contexts is that, in crowdfunding, customers buy products that do not yet exist. At the time of purchase, the products are still under development and have not been produced. Customers who engage in such a transaction make a classic investment: They allocate money with the expectation of a future benefit (utility from the finished product). The difference from more traditional forms of investment is that customers receive a product rather than a financial return for their investment. People who buy products on crowdfunding platforms are thus "customer investors" (Kuppuswamy and Bayus 2018).

Customer investors provide resources (funding) to project creators in the expectation that the project creators will use the resources to develop a product that maximises customers' utility. Customer investment thus creates a principal-agent relationship between customers and project creators: Customers act as principals, and project creators act as agents on behalf of customers (Jensen and Meckling 1976). Principal-agent relationships are commonly reported in domains that involve investors (e.g., in venture capital; Gompers 1995), but they also exist in customer settings (e.g., von Hippel 1998, Nambisan 2002).

Customer investors on crowdfunding platforms face two agency issues (Hart and Holmström 1987, Eisenhardt 1989). First, there is asymmetric information on product quality. Customers have to rely on information provided by project creators to judge product quality and on the creator's ability to deliver the promised product. Second, the specifications for a product are not fixed until the end of its crowdfunding campaign. After making an investment, customers are therefore concerned about monitoring project progress to ensure that the agent (i.e., the creator) does not change product specifications against their interests. These agency issues provide a rational motivation for why customers get actively involved in crowdfunding projects. As investors, customers interact with creators to gather information on product quality and monitor project progress to protect their investment (Gompers 1995). As customers, they attempt to influence malleable product specifications based on their own needs (Larsson and Bowen 1989, von Hippel 1998, Nambisan 2002).

Similar to the involvement of traditional investors in ventures (Bottazzi et al. 2008), the involvement of customer investors in crowdfunding projects has the potential to create value for project creators.

First, customers can help with product specifications. As investors, customers have an interest in a successful funding campaign. As customers, they possess knowledge of the application environment in which the product is eventually going to be used (von Hippel 1998). Customers' application-specific knowledge relates to their needs and the way in which a product can address these needs. Such external knowledge is a key resource for crowdfunding projects, because projects of this type are often resource-constrained and dependent upon knowledge rejuvenation (Yli-Renko et al. 2001, Priem et al. 2012). If customers share their application-specific knowledge, project creators can better adapt product specifications to customer needs. Products that are more adapted to customer needs will attract additional customers more easily and thus receive more funding.

Second, customer involvement also directly addresses the agency issues of prospective customers. When institutional investors face asymmetric information, they 
rely on the reputation of previously affiliated investors as a signal of a venture's quality (Hsu 2004). Similarly, in crowdfunding, prospective customers rely on existing customers when judging the quality of a crowdfunding project. Because customers do not carry an institutional reputation, prospective customers infer the quality of existing customers from their observable involvement in the project. Highly involved customers are a sign of quality and reduce the uncertainty surrounding product quality.

Moreover, existing customers who actively interact with project creators also reduce the additional monitoring costs for prospective customers. Monitoring the activities of ventures is a way in which traditional investors mitigate agency issues arising from the execution of a project (Gompers 1995). In crowdfunding, customer investors are the primary entity monitoring project creators. The onus is on customers to evaluate project progress and to exert influence on creators if they see their interests being threatened. Customers who want to invest in crowdfunding projects thus face monitoring costs. An existing community of involved customers is a signal to new customers that the project is being monitored diligently and that the creators are unlikely to act against the interests of the customers. This reduces the monitoring costs for prospective customers, making them more likely to invest in the project. We therefore arrive at the first hypothesis:

Hypothesis 1 (H1). During a crowdfunding campaign, greater customer input increases funding success.

Because customer involvement mitigates the agency concerns of prospective customers, its effect on funding will be greater for projects run by individuals than for projects run by teams. Teams have more resources available to run crowdfunding campaigns and develop products than individuals do. For example, teams possess more diverse knowledge, because each team member brings his or her own previous knowledge and perspective to the project (West and Anderson 1996). Teams also have larger networks that they can rely on for funding and product development support (Singh and Fleming 2010). For these reasons, prospective customers face greater uncertainty about product quality and project execution when they invest in individual projects. It is therefore important for individual projects to alleviate prospective customers' agency concerns through customer involvement (H1). In response to the uncertainty surrounding individual projects, prospective customers pay more attention to the involvement of existing customers in such projects. Every unit of input from existing customers thus has a greater impact on the investment decisions of prospective customers. Therefore, individual creators benefit more than team creators from customer involvement.
Hypothesis 2 (H2). During a crowdfunding campaign, the beneficial effect of customer input on funding success is greater for individual creators than for teams.

Part of the argument for Hypothesis 1 is that customer involvement increases funding because it allows customers to influence product specifications. Customers are experts on product applications (von Hippel 1998), meaning how products are used and how they generate value for consumers (Priem 2007). The elicitation of such application-specific information can improve product development performance (e.g., Lilien et al. 2002). However, latent application-specific information is sticky, meaning that it is costly to transfer from customers to organisations (von Hippel 1998). In crowdfunding, customers share sticky information because their investment in the project motivates them to influence product development (H1). By sharing applicationspecific information, such as requesting a certain feature, customers can reduce agency costs (residual loss) by directing product development toward their own needs.

When project creators are confronted with a large crowd of customer investors who are acting only in their own self-interest, it is hard to know which ideas have the potential to increase a product's success and which are expressions of costly niche interests (Ramdas et al. 2007, Nijssen et al. 2012). Following an unsound idea or trying to address all ideas may result in a product that is unfeasible, too costly, or unattractive to other customers. In that sense, it is not just the customers who face a moral hazard from their investment; the project creators also face a moral hazard from customers' involvement in product development. However, customers' financial stake in the project requires them to consider project failure as a potential outcome of their influence. When they submit ideas, customers therefore have to balance their interest in a product that perfectly matches their needs with feasibility and costs. Hence, customers' financial investment reduces the moral hazard for creators and leads to a stronger alignment of incentives between creators and customer investors.

The application-specific information elicited from customers is valuable to project creators, because it informs them about customer needs. However, in order for customers' application-specific information to translate into additional funding, creators need to open up product specifications to customer input. Part of the additional funding that customer involvement generates will only be realised if project creators update their products based on what they learn from customers. During crowdfunding campaigns, creators can do this by revising the product specifications in the project description. The effect of customer input on funding success is therefore mediated by the extent to which project creators revise their projects. 
Hypothesis 3 (H3). The effect of customer input on funding success is mediated by whether project creators make changes to project descriptions in response.

In the previous paragraphs, we discussed the implications of customer investor involvement in general (H1 and H2) and for the development of products through the elicitation of external information (H3). The elicitation of external information resembles traditional crowdsourcing approaches, in which a problem owner ("solution seeker") posts a problem and subsequently receives information from external problem solvers (Jeppesen and Lakhani 2010).

The benefit of crowdsourcing is traditionally understood to stem from its transformation of distant search into local search (Afuah and Tucci 2012). By interacting with a crowd of problem solvers with distant knowledge, companies can optimise over larger parts of the solution space and thereby increase the average performance of the solution search.

However, there are differences between the elicitation of external information during crowdfunding and traditional crowdsourcing approaches. Importantly, the problems faced by crowdfunding project creators, such as how to improve a given product, are difficult to define, modularise, and evaluate. However, for distant search to be transformed into local search through crowdsourcing, well-defined problems that are easy to delineate and modularise are normally required (Afuah and Tucci 2012). Taskcn (Liu et al. 2014) and TopCoder (Boudreau et al. 2011) are examples of crowdsourcing platforms with well-defined problems and clear performance criteria.

In crowdfunding, this limitation is addressed by sharing roles between problem solvers and problem owners. In crowdsourcing, problem owners and problem solvers are usually different: On the one side is a firm looking for a solution, and on the other is a crowd of problem solvers whose only involvement with the problem is through the process of solving it. In crowdfunding, the role of problem owner is shared between project creators and the crowd. Because the customer investors own part of the project and are looking to improve the product for themselves (so that they get more for their money), they are problem owners in their own right. This reduces the effort required for the project creator to communicate and modularise the problem and facilitates the evaluation, transfer, and recombination of distant knowledge, which is more challenging when the problems are complex (Afuah and Tucci 2012).

Another difference is that crowdfunding projects usually request funding for an existing product prototype. The benefit of distant search during crowdfunding thus does not pertain to coming up with an entirely new solution or product idea. Instead, it comes from identifying new domains of application for an existing product, which often drive performance improvements (e.g., Levinthal 1998). For instance, a customer who has previously been funding theatre projects may be able to help a computer game project by pointing out that an interesting story with well-developed and enacted characters might be more interesting to a wider range of people. Customers who can provide project creators with distant information about application domains as a result of their distant funding experience are therefore particularly useful to interact with.

Hypothesis 4 (H4). During a crowdfunding project, in particular, input from customers with distant funding experience increases funding success.

\section{Data}

We test the hypotheses using data from Kickstarter.com, a reward-based, all-or-nothing crowdfunding platform. ${ }^{2}$ The crowdfunding process works as follows. Entrepreneurs start with a product idea and develop the idea into a prototype. Around this prototype, entrepreneurs then build a crowdfunding campaign, comprising a description, pictures, and videos of the product. Before a campaign starts, the entrepreneur determines the two main parameters: the amount of money required to move forward with the project (the goal) and the amount of time needed to raise that money (the project duration). ${ }^{3}$ Once a crowdfunding campaign starts, it becomes publicly visible to everyone browsing the crowdfunding platform, and customers can start investing. After customers have invested in a crowdfunding campaign, they can interact with project creators in the "comments" section, which are similar to suggestion boxes on common crowdsourcing platforms (Bayus 2013, Dahlander and Piezunka 2014, Piezunka and Dahlander 2015). During the campaign, project creators can also change the description of the project. Once the crowdfunding campaign ends, project creators can no longer change the description and customers can no longer invest. If the campaign has met its goal, it is successful and the money invested is transferred to the entrepreneur.

Crowdfunding projects on Kickstarter fall into a diverse set of 13 categories, such as Art, Fashion, Games, and Technology, and come from 138 countries (the United States, the United Kingdom, and Canada having contributed the most projects). This allows us to observe customer input in a wide variety of contexts, and it avoids any industry- or market-specific biases. With an average funding goal of $\$ 23,000$, crowdfunding projects are rather small compared with fully fledged corporate product development projects and are often at the forefront of the creative industries. However, crowdfunding projects are comparable to smaller units of innovation such as patents, which are often created by individual inventors (e.g., Singh and Fleming 2010). Because many entrepreneurs use reward-based crowdfunding for presales, we treat backers as customers (Fleming and 
Sorenson 2016, Kuppuswamy and Bayus 2018); we discuss limitations of this interpretation in Section 6.

Using data from Kickstarter.com has four key advantages. First, Kickstarter projects vary with respect to the product, entrepreneur, and industry, and we observe both successful and unsuccessful projects. Second, we observe individual customer comments, which allows us to use a detailed measure of customer input. Third, the presence of changes to project descriptions is observable to us, but not to customers. Finally, there is an exogenous shock to customer input about halfway through the sampling period.

We investigate the effect of customer input on funding success with two sets of models. The first is a set of cross-sectional instrumental variable models that test whether customer input increases the likelihood of a successful campaign by using an exogenous shock to address endogeneity concerns. The second is a set of panel models that test whether customer input increases subsequent funding, after specifically controlling for social learning (e.g., herding). In the remainder of this section, we describe the sample in more detail and introduce the variables before we analyse the IV models in Section 4 and the panel models in Section 5.

\subsection{Sample}

The sample contains twice-daily observations (every 12 hours) for all 25,228 Kickstarter.com projects that started between October 2012 and May 2013. We exclude a number of projects: We remove 1,711 projects that end less than 1 month after the start of the data collection or start less than 1 month before the end of the data collection, because these projects would otherwise introduce a bias for short projects; ${ }^{4}$ we remove 41 projects whose campaign was suspended for legal reasons and 1,786 projects that were cancelled before the end of their funding phase, because we do not observe the complete funding phase and cannot conclude whether a project would have been successful had it had the complete funding phase; ${ }^{5}$ we remove 145 very short projects (less than 1 week in duration), because a meaningful operational effect resulting from customer input is less plausible in these projects; finally, we remove 54 projects that have more than 2 days of missing observations. ${ }^{6}$ The final sample contains 21,491 projects over a period of seven and a half months. On average, there are just under 100 new projects every day; $49 \%$ of these projects are successful in that they raise the amount of funding they ask for (cf. Mollick 2014). The mean crowdfunding duration is 32.60 days, and the median is 30 days.

\subsection{Dependent Variables}

To measure funding success, we use the cumulative amount of funding (in U.S. dollars) ${ }^{7}$ a project has received until period $t$ : we call this variable $F_{i, t}$. On Kickstarter, a large majority of projects offer their products or services to customers in return for money and generate sales as a result. Although exchange of money for products or services is common practice on Kickstarter, there are some exceptions. For instance, funders can pledge very small amounts of money without receiving a product in return or they may only receive replica or memorabilia. However, even in these cases, the generative mechanism leading to funding is very similar to the one that generates sales for products. ${ }^{8}$ Therefore, the amount of funding that projects receive in many cases corresponds to the amount of advance sales they have generated as a result of their innovation activity (Fleming and Sorenson 2016). Advance sales are highly predictive of postlaunch sales (Moe and Fader 2002), and an astonishing $96 \%$ of difficult technology projects on Kickstarter deliver their promised goods (Mollick 2014).

In the IV models, we investigate whether customer input increases the likelihood of a successful campaign. To do so, we create a binary variable that indicates whether a project's final funding amount is greater than or equal to its goal. Specifically, for project $i$, its final funding amount $F_{i}$, and its goal $G_{i}$ we define

$$
F S_{i}=1\left\{F_{i} \geq G_{i}\right\},
$$

where 1 condition $\}=1$ if the condition is true.

The resulting metric can be interpreted in terms of meeting sales or profitability goals. Profitability and sales benchmarks are two of the most used success metrics for innovation projects (Griffin and Page 2003; that is, "estimated sales over five years" (Lilien et al. 2002 , p. 1051)). We use $F S_{i}$ instead of the continuous ratio $F_{i} / G_{i}$, because projects tend to be either just successful or completely unsuccessful. As a result, $F_{i} / G_{i}$ takes the form of two consecutive power distributions, which complicates estimation and interpretation. Moreover, in terms of success, there is no difference between a project reaching $75 \%$ of its goal and a project reaching $25 \%$ - neither will receive any payout.

In the panel models, we investigate whether customer input increases funding in subsequent periods, for which we use the new amount of funding generated since the previous period (Zhang and Liu 2012, Burtch et al. 2013). For project $i$, this is the difference between cumulative funding levels $F_{i, t}$ in periods $t$ and $t-1$ :

$$
\nabla F_{i, t}=F_{i, t}-F_{i, t-1} .
$$

\subsection{Explanatory Variables}

We use the same explanatory variables in the IV and panel models. In the panel models, we use all timeseries observations, and in the IV models, we use the cumulative amount at the time a project reaches its goal or fails (we denote this time as $t^{F}$ ). 
Customer Input. To measure customer input, we count the comments customers have left on a project page. ${ }^{9}$ Customers can only comment on projects that they have invested in. For project $i, C_{i, t}$ is the cumulative number of customer comments up to period $t$. We use this variable directly in the panel models. In the crosssectional IV model, we use the cumulative number of customer comments up to the period in which a project reaches its funding goal: $C_{i, t^{F}}$. To give credence to the notion that customers and project creators have meaningful and project-related interactions in the project comments, we qualitatively evaluate the content of comments in Online Appendix A and show that the vast majority of comments (between $77 \%$ and $92 \%$ ) are related to either product features or project execution (e.g., delivery).

Individual Project Creator. To determine whether a project was created by an individual or by a team, we count the first singular and plural personal pronouns in the project description. A project was created by an individual (Indiv $\left.{ }_{i}:=1\right)$ if the majority of personal pronouns used in the project description are singular ("I" and "me"); a project was created by a team $\left(\right.$ Indiv $\left._{i}:=0\right)$ if the majority of personal pronouns used in the project description are plural ("we" and "us"). Of the projects in our sample, $40 \%(8,531)$ were created by individuals.

Project Revisions. To test whether project creators' response to customer input mediates the effect of input on funding, we count the changes creators make to project descriptions. We identify changes by observing the update timestamp in the intricate HTML code for the project pages. Each time the update timestamp moves forward, the project description has been changed. We observe the timestamp once every 12 hours, and it is thus a lower bound for the number of changes a project receives. Importantly, the timestamp is visible to us, but not to customers. We use the cumulative number of changes up to period $t^{F}$ in the IV models $\left(R_{i, t^{F}}\right)$ and the difference since the last period $\left(\nabla R_{i, t} \in\{0,1\}\right)$ in the panel models.

At the end of a campaign, the project page cannot be changed any more, and the product description at that point determines the eventual specifications and design of the product (Kickstarter 2014b). It is thus important for project creators to incorporate all relevant customer input into the product specifications as soon as it is provided. ${ }^{10}$

Distant Funding Experience. To test whether input from distant customers is more valuable, we measure the distance of commenting customers in terms of funding experience and then interact customer input with distance. Distant funding experience resembles measures such as "content distance" (Piezunka and Dahlander
2015), which calculate distance based on previous experience. For each project $i$ in period $t$, we perform the following steps:

- First, for each commenting customer $j$, we calculate proximal funding experience as the number of previous investments the customer has made in the same category as the focal project $\left(F E X P_{j, t, C A T_{i}}\right)$. We divide this value by customers' total funding experience $\left(F E X P_{j, t}\right)$ to get the share of customers' proximal experience (the first term in the sum). Because distance increases the utility of comments, we measure customers' funding experience at the time of their last comment on project $i: t^{*}=\max \left\{k \in T: k \leq t, \nabla C_{i, j, k} \neq 0\right\}$.

- Second, we weight the proximal funding experience of individual customers by their share of all comments (the second term in the sum; $C_{i, j, t}$ is the number of times customer $j$ has commented on project $i$ until period $t$ ).

- Third, for each project, we sum up the weighted proximal funding experiences of its commenting customers and subtract them from 1 to arrive at the weighted distant funding experience.

Formally, for project $i$ at time $t$, the weighted distance of commenting customers is defined as

$$
D_{i, t}=1-\sum_{\text {Customer } j} \frac{F E X P_{j, t^{*}, C A T_{i}}}{F E X P_{j, t^{*}}} \times \frac{C_{i, j, t}}{C_{i, t}} .
$$

We use $D_{i, t^{F}}$ in the IV models and $D_{i, t}$ in the panel models. Although we implicitly control for customer seniority in this formula by calculating distance relative to $F E X P_{j, t}$ in the denominator (total funding experience of customer $j$ across categories), we also run an additional analysis explicitly controlling for weighted customer funding experience, and all results hold.

\section{Instrumental Variable Models}

In our first set of models, we examine the effect of customer input on the likelihood of funding success using an instrumental variable to control for creator ability and project quality. We describe specification and results of the IV models in this section before we turn to the panel models in Section 5.

\subsection{Instrumental Variable}

As an instrument, we use the release of the Kickstarter Mobile app on February 14, 2013. The app allows project creators and customers to interact easily, even when there is no computer available (Figure B.1 in Online Appendix B). As a result, the mobile app increases the amount of customer input projects receive in all categories (Figure 1). As the app's release is independent of individual creators' ability and project quality, the resulting increase in customer input is also independent of creator ability and project quality. Therefore, any change in the likelihood of funding 
Figure 1. Average Customer Input by Category Before and After the Release of the Mobile App

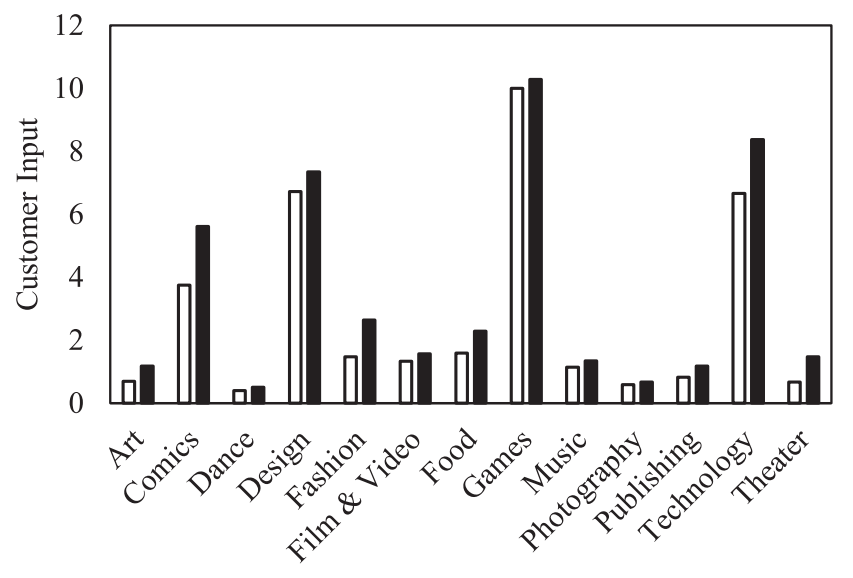

$\square$ Before Mobile App Release After Mobile App Release

success as a consequence of increased customer input through the mobile app is exogenous, and we can be confident that this is not a by-product of unobserved creator ability or project quality. We implement this procedure in a two-stage estimation (Wooldridge 2010). In the first stage, we estimate the exogenous increase of customer input as a result of the app release. In the second stage, we use the estimated exogenous increase in customer input to estimate its impact on funding success. The second-stage results we obtain are therefore not biased by creator ability and project quality. In the following paragraphs, we describe and evaluate the instrumental variable in detail.

"Kickstarter isn't a store" where customers spontaneously buy products, but a collaboration and codevelopment platform (Strickler et al. 2012). A main purpose of the mobile app is to let project creators and customers easily keep track of their projects and interact with each other (Kickstarter Executive 2014). The app's commenting function is easy to use (Figure B.1 in Online Appendix B), and no repeated login is required. We evaluate the quality of the instrumental variable in a model without controls (model not shown). We report a significant positive effect of the introduction of the mobile app on customer input $\left(\beta_{1}=0.55, p<0.01\right)$ and a first-stage F-statistic of 24.86, well above the common threshold of 10 and indicating a strong instrumental variable. According to the control function approach (see Section 4.3), the second stage includes the estimated first-stage residuals $\left(\hat{u}_{i}\right)$ to control for unobserved confounders. We find significant residuals in the second stage, which indicates an endogeneity problem and thus justifies the use of an instrumental variable $\left(\gamma_{U}=-0.30, p<0.01\right)$ (Wooldridge 2010).

It is possible that we are observing a seasonal trend that coincides with the introduction of the mobile app. Because we do not possess data on the same time frame during previous years, we must evaluate the trend as we observe it in the data. Figure 2 displays the development of the 30-day moving average of the weighted daily average customer input (solid) and new projects (dotted) by project start dates. The time frame covered by the sample is centred approximately on the release of the mobile app (dashed vertical line). There is a noticeable and steady increase in customer input for projects starting roughly 15 days before the introduction of the mobile app (the median project duration is 30 days). This increase quickly stabilises at around 150\% of the average prerelease customer input. We also estimate the full model without the 2012 holiday seasonduring which there was less customer input-and the results hold. We are therefore confident that we are observing not a seasonal trend, but rather a substantial increase in customer input due to the release of the mobile app.

Although the app also allows project funding, there is evidence that this is not a violation of the exclusion restriction. First, the funding feature of the mobile app was very hard to use at the time, as customers had to have an Amazon account and to repeatedly remember and enter their Amazon credentials (Figure B.1 in Online Appendix B). Although this may not be a major problem when using an internet browser (due to cookies and stored passwords), it significantly impeded funding through the mobile app. As one customer noted: "Good app, but I wish it was possible to donate without having to create an account and go through Amazon payments. I think this turns a lot of potential backers off" (iTunes user, August 27, 2014). To alleviate the difficulty of the funding function, Kickstarter later rolled out its own payment system, replacing the previously used Amazon payment system (Kickstarter Executive 2014). ${ }^{11}$ Second, crowdfunding customers are usually highly engaged and spend a lot of time researching different projects as "shadow artists." Because of the uncertain nature of Kickstarter projects (the products still have to be developed), customers need to look at projects with due diligence to understand the associated risks before funding them. This is reflected in project descriptions, which often span several pages and contain multiple pictures, videos, and even blueprints. However, diligent evaluation of such detailed information is very difficult on the small screens of mobile phones. For these reasons, it is unlikely that the app independently attracted significant funding.

\subsection{Control Variables}

In addition to the instrument, we include several control variables in the model to account for potential confounders - in particular, creator ability, project quality, and project complexity.

We control for the number of videos in project descriptions. Videos are difficult to make and require 
Figure 2. Weighted Daily Average Customer Input and New Projects by Project Start Dates

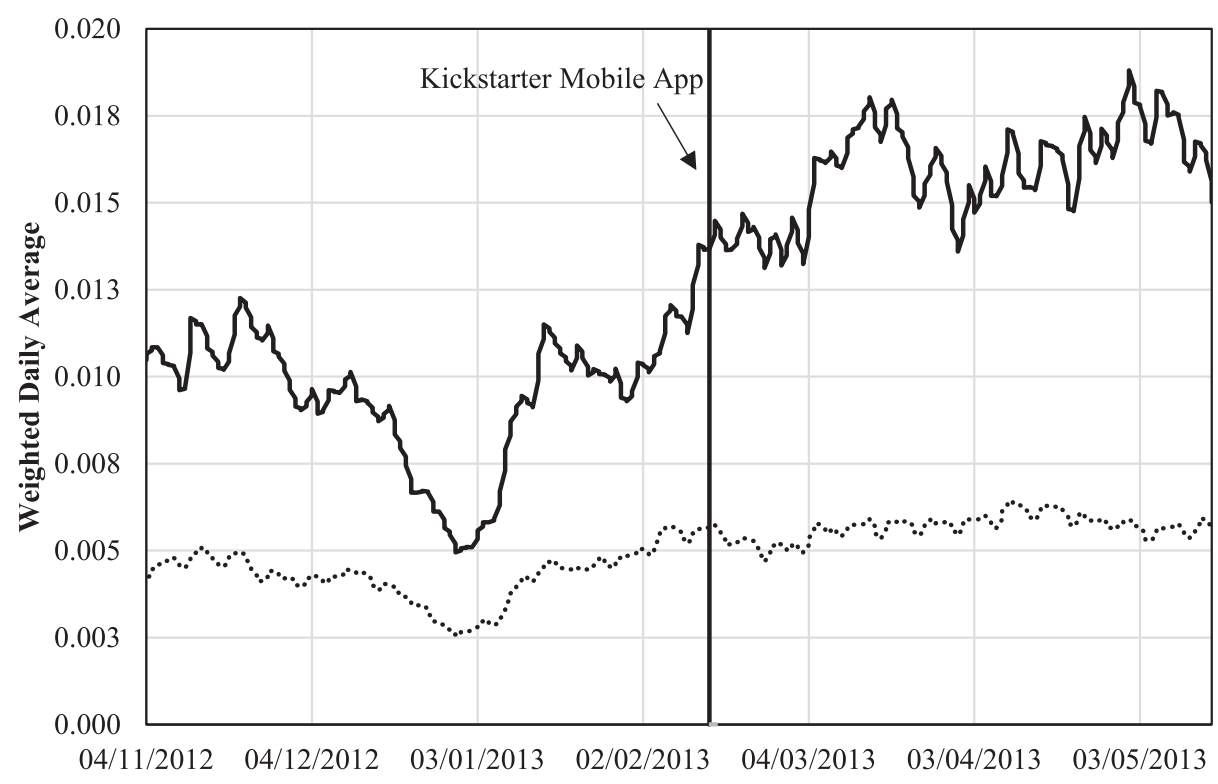

significant work and expenses from project creators (equipment, scripts, prototypes, locations, filming, cutting, sound, etc.). At the same time, videos are one of the most important factors when customers decide whether to fund a project (Kickstarter 2014a). Therefore, the number of videos in project descriptions allows us to control for creator ability and project appeal (Colombo et al. 2014). We also control for whether a project has a separate website, which requires capital and effort to create and maintain and is a sign of high-quality projects (Colombo et al. 2014).

We control for the extent of projects' risks section (in terms of the number of words). In the risks section, project creators are asked to describe all potential risks associated with their project, reflecting their "ability to complete the project as promised and whether ... the creator is being open and honest about the risks and challenges they face" (Strickler et al. 2012). Creators' openness about the risks associated with their project is a good control for their understanding of the project as well as for their own belief in the likelihood of success. Risk is also an important outcome of complexity, and projects with more associated risks are thus likely to be more complex (Bosch-Rekveldt et al. 2011).

We control for whether a project is run by an incorporated organisation with a legal name (e.g., Limited, Ltd, LP). The organisational background of creators is a good control for their resources, their experience with new product development, and their ex-ante funding network. Moreover, projects of incorporated organisations may be more complex than other projects. We also control for project creators' prior crowdfunding experience as the number of previous projects they have created.
We include the natural logarithm of projects' goal in US dollars. The goal is project creators' realistic expectation of the minimum feasible project budget. The budget allows us to control for the size and complexity of the project (Müller and Turner 2007, Bosch-Rekveldt et al. 2011). For instance, a project with a funding target of $\$ 20,000$ (a board game) is less complex than a project with a target of $\$ 100,000$ (sunglasses with inbuilt headphones) and a project with a target of $\$ 1,000,000$ (a computer game). Similarly, we control for project duration, which is also a common measure of project complexity (Bosch-Rekveldt et al. 2011).

We control for previous customer engagement as the sum of customers' previous interactions with other projects. Certain customers may be particularly engaged with projects, and some projects may attract such customers more than others.

Finally, we control for project category. Kickstarter categories include Photography, Dance, Games, Publishing, Music, Comics, Film \& Video, Design, Technology, Fashion, Theater, Art, and Food. Project frequencies, number of funding transactions, and amount of customer input vary significantly across categories (Figure B.2 in Online Appendix B). The base category for all analyses is Design, because Design projects are well represented in the sample and attract a good degree of comments while avoiding the extremes of other categories (e.g., Games).

\subsection{Model Specification}

Funding success is a dichotomous variable; hence, a logit model is preferred over a linear probability model (Pindyck and Rubinfeld 1991). To control for endogeneity, we use a control function approach in a two-stage 
estimation (Liu et al. 2010, Wooldridge 2010), which is the preferred method when dealing with endogeneity issues in logit models (Guevara and Ben-Akiva 2012). In the first stages, we regress customer input and project revisions on the exogenous variables and the instrument $\left(Z_{i}\right)$ in an ordinary least-squares model. We then use the predicted residuals of the first stages $\left(\hat{u}_{i}\right)$ in the secondstage logit estimations. The second-stage estimators are consistent up to scale (Wooldridge 2010); in the case of logit models, the obtained estimators are smaller than the true effect sizes (Guevara and Ben-Akiva 2012). As the obtained standard errors may not be strictly valid, we use a nonparametric bootstrap to obtain correct standard errors in the second stages (Wooldridge 2010). We arrive at the following regressions for $\mathrm{H} 1$ and $\mathrm{H} 4$ in the first and second stages, respectively (IV Model 1): ${ }^{12}$

$$
\begin{aligned}
C_{i, t^{F}}= & \beta_{0}+\beta_{1} Z_{i}+\beta_{2} D_{i, t^{F}}+\beta_{X} X_{i}+u_{i} \\
F S_{i}= & \gamma_{0}+\gamma_{1} C_{i, t^{F}}+\gamma_{2} D_{i, t^{F}}+\gamma_{3} C_{i, t^{F}} \times D_{i, t^{F}}+\gamma_{U} \hat{u}_{\mathrm{i}} \\
& +\gamma_{U D} \hat{u}_{\mathrm{i}} \times D_{i, t^{F}}+\gamma_{X} X_{i}+v_{i}
\end{aligned}
$$

where $C_{i, t^{F}}$ is customer input, $Z_{i}$ is the instrument, $D_{i, t^{F}}$ is the distance of commenting customers, and $X_{i}$ is a vector of control variables. To estimate the interaction between customer input and distance correctly, we also include an interaction between the estimated first-stage residuals and distance $\left(\hat{u}_{\mathrm{i}} \times D_{i, t^{F}}\right)$ in the second stage (for a similar approach to endogenous interaction terms, see Liu et al. 2010).

To test whether individual projects benefit more from customer input (H2), we include an indicator variable for individual projects $\left(\right.$ Indiv $\left._{i}\right)$ in both stages and interact it with customer input in the second stage (IV Model 2):

$$
\begin{aligned}
C_{i, t^{F}}= & \beta_{0}+\beta_{1} Z_{i}+\beta_{2} D_{i, t^{F}}+\beta_{3} \operatorname{Indiv}_{i}+\beta_{X} X_{i}+u_{i} \\
F S_{i}= & \gamma_{0}+\gamma_{1} C_{i, t^{F}}+\gamma_{2} D_{i, t^{F}}+\gamma_{3} C_{i, t^{F}} \times D_{i, t^{F}}+\gamma_{4} \operatorname{Indiv}_{i} \\
& +\gamma_{5} C_{i, t^{F}} \times \operatorname{Indiv}_{i}+\gamma_{U} \hat{u}_{\mathrm{i}}+\gamma_{U D} \hat{u}_{\mathrm{i}} \times D_{i, t^{F}} \\
& +\gamma_{\mathrm{UI}} \hat{u}_{\mathrm{i}} \times \operatorname{Indiv}_{i}+\gamma_{X} X_{i}+v_{i} .
\end{aligned}
$$

We next describe how we test in the cross-sectional IV model whether project revisions mediate the effect of customer input on funding success (H3). In the initial model (IV Model 1), funding success is the dependent variable, customer input is the explanatory variable, and we are interested in $F S_{i}=\gamma_{C} C_{i, t}$. In a mediation model (e.g., Singh and Fleming 2010), a mediator is a third variable "which represents the generative mechanism through which the focal [explanatory] variable $\left[C_{i, t^{F}}\right]$ is able to influence the dependent variable $\left[F S_{i}\right]$ of interest" (Baron and Kenny 1986, p. 1173). In our case, the mediator is the number of project revisions $\left(R_{i, t^{F}}\right)$, and we are interested in $R_{i, t^{F}}=\delta C_{i, t^{F}}$ and $F S_{i}=$ $\gamma_{R} R_{i, t^{F}}$. We again use the introduction of the mobile app as an instrument, but this time we use it for the mediator
$R_{i, t^{F}}$. Because project creators cannot revise their project using the app, there is no direct causal link between the introduction of the app and increased revisions. Therefore, the number of revisions is independent of the instrument and can only be influenced by increased customer input $(\partial)$. Any effect of the instrumented number of project revisions on funding success then represents $\gamma_{R}$ as a result of $\partial$. We thus arrive at the following models for $\mathrm{H} 3$ in the first and second stage, respectively (IV Model 3):

$$
\begin{gathered}
R_{i, t^{F}}=\beta_{0}+\beta_{1} Z_{i}+\beta_{X} X_{i}+u_{i} \\
F S_{i}=\gamma_{0}+\gamma_{1} R_{i, t^{F}}+\gamma_{U} \hat{u}_{\mathrm{i}}+\gamma_{X} X_{i}+v_{i} .
\end{gathered}
$$

We exclude 218 outlier projects whose customer input is greater than or equal to the 99th percentile (96 comments) to avoid nonconvergence due to quasicomplete separation during the logit estimation (Altman et al. 2004). Because projects above the 99th percentile are $76 \%$ more likely to be successful than projects below ( $86 \%$ vs. $49 \%$ ), the exclusion of outliers also allows us to report more conservative estimates.

\subsection{Results}

Table 1 shows the descriptive statistics and Table 2 the correlations for the IV models without outliers. We report no multicollinearity issues.

Table 3, IV Model 1, shows the results relevant to H1 and $\mathrm{H} 4$. We find a significant positive effect of customer input on funding success (H1) while controlling for unobserved confounders in the second stage $\left(\gamma_{1}=0.36, p<0.01\right)$. Every comment that is posted before a project is funded increases by $43 \%$ the likelihood that the project will eventually exceed its target. ${ }^{13}$ The interaction between distant funding experience and customer input (H4) is also significant $\left(\gamma_{3}=0.23\right.$, $p<0.01)$. A one-unit increase in distant funding experience results in an additional 26\% increase in the likelihood of funding success per comment. Although all customer input increases the likelihood of a successful campaign, input from customers with distant funding experience does so at a faster rate (see Figure 3).

In IV Model 2, the moderating effect of individual project creators $(\mathrm{H} 2)$ in the second stage is significant and positive $\left(\gamma_{5}=0.03, p<0.01 ; 3 \%\right.$ additional increase in funding likelihood for each comment). As can be seen in the second column, projects run by a single individual are generally less likely to be successful $\left(\gamma_{4}=-0.33, p<0.05 ; 28 \%\right.$ less likely). The larger positive effect of customer input for individual creators thus partly compensates for their disadvantage.

To test the mediating role of project revisions (H3), we regress project revisions on the instrumental variable. First, we again evaluate the quality of the instrumental variable in a model without controls. We 
Table 1. Descriptive Statistics for the IV Models $(n=21,273)$

\begin{tabular}{lrccr}
\hline Variables & Mean & Standard deviation & Minimum & Maximum \\
\hline Funding success & 0.48 & 0.50 & 0 & 1 \\
Mobile app & 0.51 & 0.50 & 0 & 1 \\
Customer input & 2.54 & 8.03 & 0 & 91 \\
Distant funding experience & 0.73 & 0.39 & 0 & 1 \\
Individual creator & 0.40 & 0.49 & 0 & 1 \\
Project revisions & 3.43 & 3.48 & 0 & 47 \\
Duration & 32.58 & 10.36 & 8 & 61 \\
Creator experience & 0.09 & 0.54 & 0 & 22 \\
Goal (ln) & 8.57 & 1.46 & 0 & 17 \\
Currency (GBP $=1)$ & 0.10 & 0.30 & 0 & 1 \\
Videos & 1.06 & 0.92 & 0 & 23 \\
Incorporated & 0.02 & 0.14 & 0 & 1 \\
Website & 0.86 & 0.35 & 0 & 1 \\
Risks section & 142.35 & 117.72 & 0 & 7,291 \\
Previous customer engagement & 1.56 & 6.09 & 111 \\
\hline
\end{tabular}

find the expected significant positive effect on project revisions $\left(\beta_{1}=0.61, p<0.01\right)$ and a first-stage F-statistic of 167.63 , well above the common threshold of 10 and indicating a strong instrumental variable. We find significant residuals in the second stage, which indicate an endogeneity problem and thus justify the use of an instrumental variable $\left(\gamma_{U}=-0.36, p<0.01\right)$. In the full IV Model 3 with all controls, the instrumented effect of project revisions on funding success is positive and significant while controlling for unobserved confounders $\left(\gamma_{1}=0.34, p<0.01\right)$. Supporting H3, every project revision increases the likelihood of funding success by $40 \%$ (see Figure 4 ).

We conduct a number of additional empirical analyses to check the robustness of the results. First, we also estimate a multinomial logit model of funding success. To do so, we partition funding success into four categories: substantially under target (less than
$75 \%$ of the goal was raised), slightly under target (more than $75 \%$ but less than $100 \%$ of the goal was raised), slightly over target (more than $100 \%$ but less than $112 \%$ of the goal was raised; $112 \%$ is the 75 th percentile of the funding ratio), and substantially over target (more than $112 \%$ of the goal was raised). Customer input significantly increases the chances of a project being in any higher funding level, especially for the $>112 \%$ level.

Second, more experienced creators may set lower goals to increase their chances of success. In addition to controlling for goal, we examine the correlation between project creators' preparedness (including funding experience, number of pictures, and length of the risks section) and project goal. The correlations are significantly positive $(p<0.01)$, suggesting that experienced and well-prepared creators set higher goals.

Third, there was a different payment system in place for UK-based projects during the data-collection time

Table 2. Correlation Matrix for the IV Models $(n=21,273)$

\begin{tabular}{|c|c|c|c|c|c|c|c|c|c|c|c|c|c|}
\hline Variables & 1 & 2 & 3 & 4 & 5 & 6 & 7 & 8 & 9 & 10 & 11 & 12 & 13 \\
\hline (1) Funding success & 1 & & & & & & & & & & & & \\
\hline (2) Customer input & $0.19 * * *$ & 1 & & & & & & & & & & & \\
\hline $\begin{array}{l}\text { (3) Distant funding } \\
\text { experience }\end{array}$ & $-0.29^{* * *}$ & $-0.37^{* * *}$ & 1 & & & & & & & & & & \\
\hline (4) Individual creator & $-0.08^{* * *}$ & $-0.07^{* * *}$ & $0.06^{* * *}$ & 1 & & & & & & & & & \\
\hline (5) Project revisions & $-0.07^{* * *}$ & $0.27^{* * *}$ & $-0.19^{* * *}$ & $-0.05^{* * *}$ & 1 & & & & & & & & \\
\hline (6) Duration & $-0.12^{* * *}$ & $0.03^{* * *}$ & $-0.03^{* * *}$ & $-0.03^{* * *}$ & $0.12^{* * *}$ & 1 & & & & & & & \\
\hline (7) Creator experience & $0.03^{* * *}$ & $0.06^{* * *}$ & 0.01 & 0 & $-0.02^{* * *}$ & $-0.04^{* * *}$ & 1 & & & & & & \\
\hline (8) Goal (ln) & $-0.26^{* * *}$ & $0.22^{* * *}$ & $-0.18^{* * *}$ & $-0.14^{* * *}$ & $0.31^{* * *}$ & $0.21^{* * *}$ & $-0.09^{* * *}$ & 1 & & & & & \\
\hline (9) Currency $(G B P=1)$ & $-0.08^{* * *}$ & 0 & $0.03^{* * *}$ & -0.01 & $0.02^{* * *}$ & 0 & 0 & 0 & 1 & & & & \\
\hline (10) Videos & $0.06^{* * *}$ & $0.11^{* * *}$ & $-0.13^{* * *}$ & $-0.08^{* * *}$ & $0.11^{* * *}$ & $0.02^{* * *}$ & $-0.02^{* * *}$ & $0.18^{* * *}$ & $-0.02^{* * *}$ & 1 & & & \\
\hline (11) Incorporated & $-0.02^{* * *}$ & $0.04^{* * *}$ & $-0.04^{* * *}$ & $-0.08^{* * *}$ & $0.04^{* * *}$ & $0.01^{*}$ & -0.01 & $0.09^{* * *}$ & 0 & $0.02^{* *}$ & 1 & & \\
\hline (12) Website & $0.1^{* * *}$ & $0.07^{* * *}$ & $-0.1^{* * *}$ & $-0.05^{* * *}$ & $0.07^{* * *}$ & $0.01^{*}$ & 0.01 & $0.08^{* * *}$ & $-0.02^{* * *}$ & $0.12^{* * *}$ & $0.03^{* * *}$ & 1 & \\
\hline (13) Risks section & -0.01 & $0.09^{* * *}$ & $-0.09^{* * *}$ & $-0.06^{* * *}$ & $0.12^{* * *}$ & $0.03^{* * *}$ & -0.01 & $0.21^{* * *}$ & 0.01 & $0.11^{* * *}$ & $0.03^{* * *}$ & $0.07^{* * *}$ & 1 \\
\hline $\begin{array}{l}\text { (14) Previous } \\
\text { customer } \\
\text { engagement }\end{array}$ & $0.06^{* * *}$ & $0.18^{* * *}$ & $-0.14^{* * *}$ & $-0.01^{*}$ & $0.09^{* * *}$ & 0.01 & $0.05^{* * *}$ & $0.04^{* * *}$ & $0.02^{* * *}$ & $0.03^{* * *}$ & $0.03^{* * *}$ & $0.02^{* * *}$ & $0.03^{* * *}$ \\
\hline
\end{tabular}

${ }^{*} p<0.10 ;{ }^{* *} p<0.05 ;{ }^{* * *} p<0.01$. 


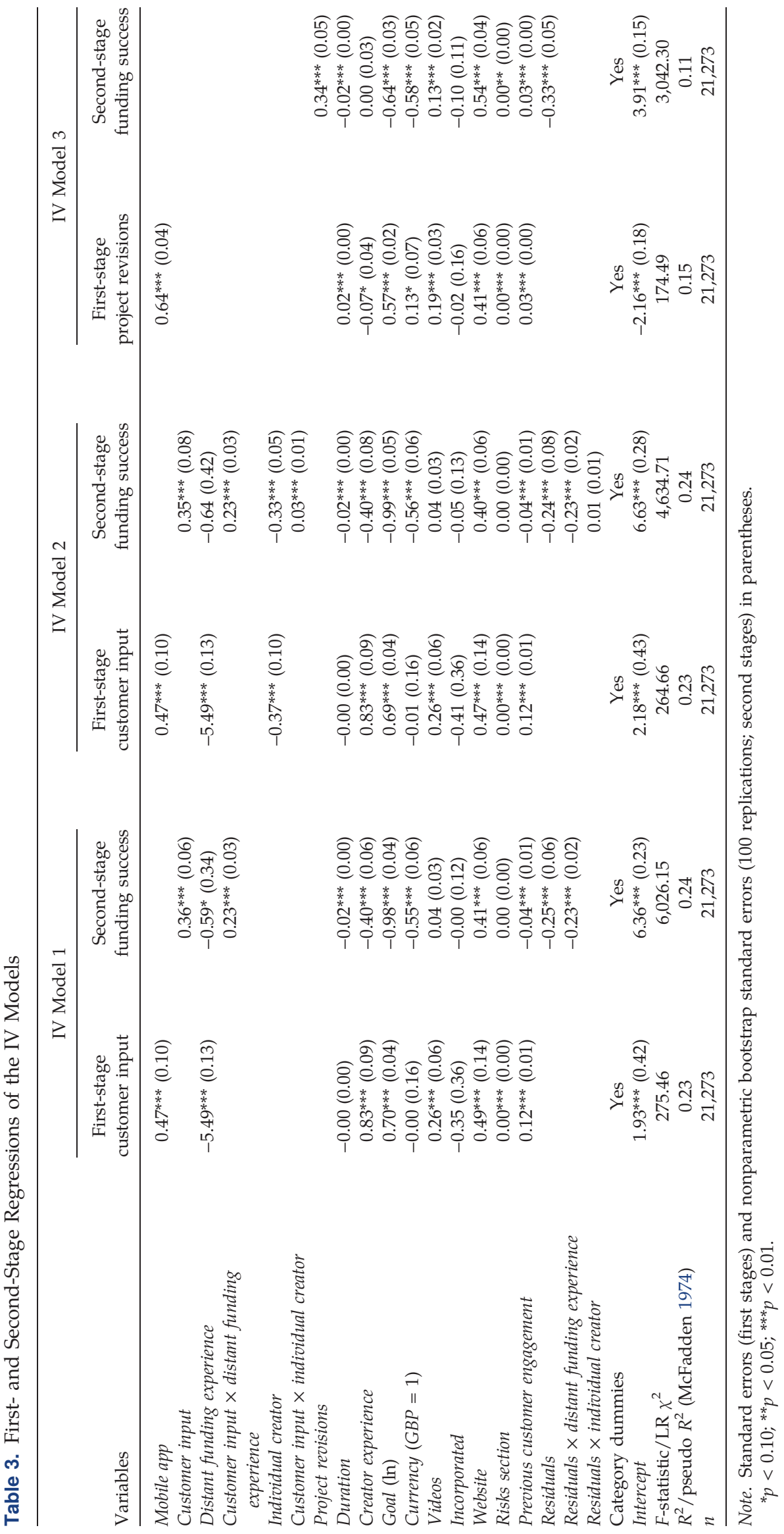


Figure 3. Predicted Likelihood of Funding Success at Different Levels of Customer Input and Distance

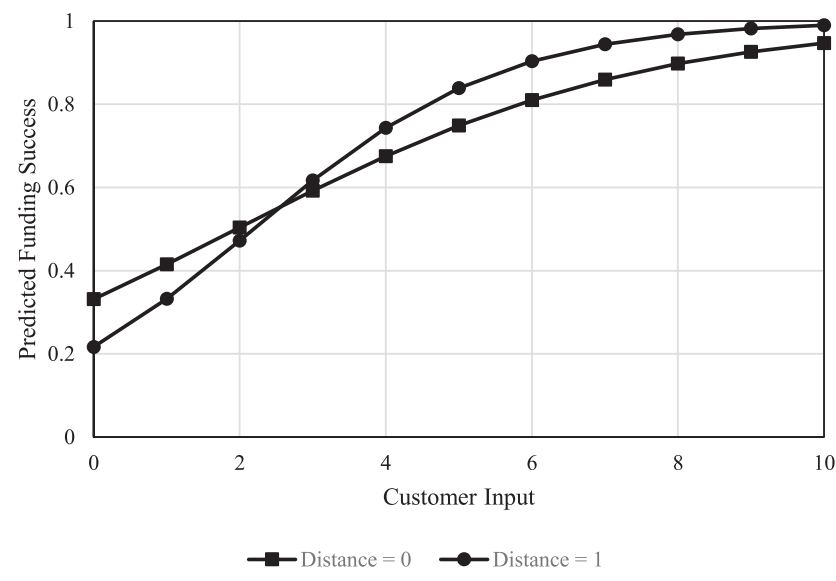

Note. All other variables at their means.

frame. This could bias the results of the two-stage estimation procedure with the mobile app as the instrument. We run the IV model without UK-based projects and find a significantly positive effect of customer input $\left(\gamma_{1}=0.32, p<0.01\right)$.

Fourth, we use a nonparametric matching approachnamely, coarsened exact matching (CEM) (Blackwell et al. 2009, Iacus et al. 2012) — to further ensure that our results are not confounded by the sheer number of customers. CEM is a statistical technique for modifying observational data to improve causal inference and to reduce model dependence. This is achieved by pruning observations from the data so that selected pretreatment confounders are balanced between treated and control groups. As such, the remaining data are better balanced and more similar to the empirical distributions of the covariates in the groups. In our case, we use the CEM procedure to create a balanced subsample in which we compare projects with similar numbers of customers but varying amounts of customer input. Specifically, we put projects in one of three groups to

Figure 4. Predicted Likelihood of Funding Success at Different Levels of Project Revisions

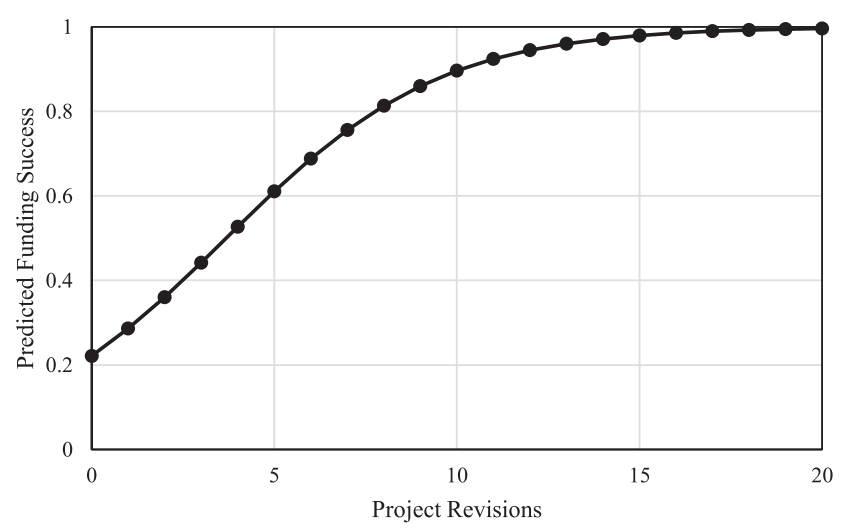

Note. All other variables at their means. account for the long tail of the customer-input distribution (cf. Iacus et al. 2019): no customer input, a medium amount of customer input (1-12 comments), and a large amount of customer input (more than 13 comments). We then match projects across these groups based on their number of customers. ${ }^{14}$ We reestimate the IV models in the balanced subsample and all results hold at the same levels of significance (see Online Appendix $\mathrm{C}$ ), apart from the individual interaction effect, which is positive but not significant. Given that it is significant in all other models and robustness checks, we are confident that the reason here is mainly the reduced sample size.

Lastly, we also run separate models for the following scenarios: (1) We treat all suspended and cancelled projects as failed projects; (2) we include customer funding experience to control explicitly for customer seniority; and (3) we exclude the 2012 holiday season to check the validity of the instrumental variable. The results hold in all scenarios.

\section{Panel Models}

In our second set of analyses, we use panel models to exploit the longitudinal nature of our sample. As a result of this, we are able provide additional support for the initial results of the IV models and analyse the effect of customer input on funding in a dynamic way. The panel models add to the robustness of our results in three ways: (1) The temporal separation of customer input and subsequent funding allows us to rule out reverse causality; (2) project fixed effects, which remove all constant effects from the estimation, allow us to control for project quality and creator ability in a different way than with the instrumental variable; and (3) we can explicitly control for social learning.

The panel data contain an unbalanced set of 12-hour observations for each project, from the project's first public appearance on Kickstarter.com until the campaign ends. As some variables require two lags, the first two observations for each project are discarded. The total number of observations available for estimation is $1,387,364$. The dependent variable in all panel models is new funding received since the previous period $\left(\nabla F_{i, t}\right)$.

\subsection{Control Variables}

To rule out confounding factors, we include several control variables in $t-1$, which is when customers make the funding decisions that affect the contemporary dependent variable $\nabla F_{i, t}$.

Most importantly, we control for social learning, which occurs when people base their decisions on the decisions of others and which often leads to herding (Banerjee 1992). There are two forms of social learning: observational learning (observing others' decisions) and 
learning through communication (being told about others' decisions) (Bikhchandani et al. 1992, Bikhchandani et al. 1998, Cai et al. 2009).

Observational learning is "theoretically a function of the number of contributors [backers] the project has received in the past" (Kuppuswamy and Bayus 2017, p. 74). Thus, we control for observational learning with cumulative customers $\left(B_{i, t-1}\right)$ (Zhang and Liu 2012) and new customers $\left(\nabla B_{i, t-1}\right)$. The former captures learning in a more static sense (the number of backers grows continuously), and the latter captures it in a more dynamic sense (momentum, rush into a project). We also control for herding around the average amount of funding (Smith et al. 2015) with the lagged average $\left(\bar{F}_{i, t-1}\right)$.

Learning from communication (the second form of social learning) is often operationalised as word of mouth (Kuppuswamy and Bayus 2017). To capture word of mouth around Kickstarter projects, we control for cumulative Facebook shares $\left(F B S_{i, t-1}\right)$. A Facebook share occurs when a project's Kickstarter URL is posted on Facebook, for example, in a status update (these data come directly from Facebook, which tracks all URLs mentioned on the platform).

Apart from learning, herding can also occur because of salience (popular projects are more visible) and payoff externalities (customers receive secondary benefits from contributing to a well-funded project) (Bikhchandani et al. 1992, Cai et al. 2009). We control for salience with a variable that indicates whether a project is "in the top 50 of all active projects in terms of backers added over the prior week" (TOP $\left.P_{i, t-1}\right)$ (Kuppuswamy and Bayus 2017, p. 78). Active marketing by the project creators may also increase salience, and we include the number of new posts from the creators $\left(\nabla P_{i, t-1}\right)$ to control for that. Project creators use posts to publicly inform existing and prospective customers about the project status. We also control for pay-off externalities that may arise as a project gets closer to its goal and eventually surpasses it, using a stepped funding ratio variable that increases by 1 for every $20 \%$ of the goal reached $\left(F R_{i, t-1}\right)$ (Kuppuswamy and Bayus 2017).

Lastly, we include a variable that tracks the length of time a campaign has been live $\left(T I M E_{i, t}\right.$ and $T I M E_{i, t}^{2}$ to capture curvilinear effects) as well as week dummies $\left(a_{w}\right)$ to control for seasonality.

\subsection{Model Specification}

The fixed-effects model for $\mathrm{H} 1$ is

$$
\begin{aligned}
\nabla F_{i, t}= & \beta_{1} C_{i, t-1}+\beta_{X} X_{i, t-1}+\beta_{T 1} T I M E_{i, t}+\beta_{T 2} T I M E_{i, t}^{2} \\
& +\beta_{W} a_{w}+a_{i}+u_{i, t}
\end{aligned}
$$

with $C_{i, t-1}$ the once-lagged cumulative amount of customer input, all once-lagged controls in $X_{i, t-1}$, and fixed effects $a_{i}$.
To test H2, we interact cumulative customer input with the indicator variable for individual projects $\left(\right.$ Indiv $\left._{i}\right)$. The separate, noninteracted, constant term Indiv ${ }_{i}$ drops out because it is included in the fixed effects $a_{i}$ :

$$
\begin{aligned}
\nabla F_{i, t}= & \beta_{1} C_{i, t-1}+\beta_{2} \operatorname{Indiv}_{i} \times C_{i, t-1}+\beta_{X} X_{i, t-1} \\
& +\beta_{T 1} T_{I M E} E_{i, t}+\beta_{T 2} T_{I M E}^{2}+\beta_{W} a_{w}+a_{i}+u_{i, t} .
\end{aligned}
$$

To test H3, we analyse the interaction of input and revisions using a two-step procedure (Pierce et al. 2015; Osadchiy et al. 2016; Godinho de Matos et al. 2017). First, we split $C_{i, t-1}$ into its twice-lagged and differential component:

$$
C_{i, t-1}=\nabla C_{i, t-1}+C_{i, t-2} .
$$

We then interact project revisions $\left(\nabla R_{i, t-1}\right)$ with the twice-lagged cumulative customer input $\left(C_{i, t-2}\right)$, which effectively replace $C_{i, t-1}$ as the main explanatory variable $\left(\nabla C_{i, t-1}\right.$ is kept to make the models comparable):

$$
\begin{aligned}
\nabla F_{i, t}= & \beta_{1} \nabla C_{i, t-1}+\beta_{2} C_{i, t-2}+\beta_{3} \nabla R_{i, t-1}+\beta_{4} C_{i, t-2} \times \nabla R_{i, t-1} \\
& +\beta_{X} X_{i, t-1}+\beta_{T 1} T I M E_{i, t}+\beta_{T 2} T I M E_{i, t}^{2}+\beta_{W} a_{w}+a_{i} \\
& +u_{i, t} .
\end{aligned}
$$

The rationale is that customer input requires project changes to affect funding. Thus, we test the effect of twicelagged input on current funding via once-lagged project changes $\left(\beta_{4}\right)$ : Cumulative customer input $(t-2) \rightarrow$ Revisions $(t-1) \rightarrow$ Funding $(t)$. Because of the temporal separation, revisions in $t-1$ cannot affect input in $t-2$.

To test $\mathrm{H} 4$, we interact cumulative customer input with the distance measure $\left(D_{i, t-1}\right)$ :

$$
\begin{aligned}
\nabla F_{i, t}= & \beta_{1} C_{i, t-1}+\beta_{2} D_{i, t-1}+\beta_{3} D_{i, t-1} \times C_{i, t-1}+\beta_{X} X_{i, t-1} \\
& +\beta_{T 1} T I M E_{i, t}+\beta_{T 2} T I M E_{i, t}^{2}+\beta_{W} a_{w}+a_{i}+u_{i, t} .
\end{aligned}
$$

\subsection{Results}

Table 4 shows the descriptive statistics for the panel models. We report no multicollinearity issues. The dependent variable is new funding since the last period $\left(\nabla F_{i, t}\right)$. Table 5 shows the main estimation results. All standard errors are clustered at the project level and robust to heteroscedasticity and autocorrelation (Wooldridge 2010).

To test H1, we regress new funding since the last period on once-lagged customer input. The $\beta_{1}$-coefficient in Model 1 has a value of 1.03 and is significant $(p<0.01)$, supporting H1. A single comment by one user in $t-1$ immediately creates $\$ 1.03$ of additional funding in $t$. This effect is cumulative and increases every 12 hours: For a project that runs for 32 days (the average), a comment that is posted halfway through the project subsequently generates $\$ 32.96$ of additional funding, whereas a comment that is posted at the beginning of the same project generates $\$ 65.92$. For the longest projects (6061 days, 1,342 projects), the cumulative effect increases to 
Table 4. Descriptive Statistics for the Panel Models $(n=1,387,364)$

\begin{tabular}{lrrrr}
\hline Variables & Mean & Standard deviation & Minimum & Maximum \\
\hline Cumulative customer input & 14.44 & 441.86 & 0 & 98,434 \\
New project revision & 0.07 & 0.26 & 0 & 1 \\
Distant funding experience & 0.77 & 0.38 & 0 & 1 \\
Cumulative customers & 82.35 & 724.28 & 0 & 91,585 \\
New customers & 1.97 & 25.40 & -342 & 16,783 \\
Cumulative funding & $5,877.79$ & $49,901.08$ & 0 & $5,702,153$ \\
New funding & 146.55 & $1,801.56$ & $-83,913$ & 923,169 \\
Average funding & 63.68 & 103.47 & 0 & 5,005 \\
Cumulative Facebook shares & 78.56 & 504.54 & 0 & 44,522 \\
Top 50 & 0.02 & 0.13 & 0 & 1 \\
New posts & 0.05 & 0.24 & 0 & 34 \\
\hline
\end{tabular}

up to $\$ 125.66$. These are average values, so some comments may generate more, whereas others may generate less. Importantly, the average customer investment at the end of a project is $\$ 68.67$, so a single comment posted early in the campaign can generate additional funding in the same order of magnitude as an additional customer.

To test H2, we include an interaction between customer input and the individual creator indicator variable in Model 2. The interaction is significant $\left(\beta_{2}=4.09\right.$, $p<0.01$ ), supporting the hypothesis that individual creators benefit more from customer input, because agency costs play a greater role for their customers.

To test the mediating role of project revisions (H3), we first split once-lagged cumulative customer input into its components (twice-lagged cumulative customer input and the difference between the two periods) and compare it to the previous results (Model 3A). The effect of twice-lagged cumulative customer input is slightly weaker than once-lagged cumulative customer input $\left(\beta_{2}=1.02, p<0.01\right)$, but the difference between the two periods is not significant. Then, we include project revisions and its interaction with twicelagged cumulative customer input in Model 3B. Now, the effect of twice-lagged cumulative customer input is nonsignificant, and the interaction between input and revisions is strongly significant and very similar to estimated effect of twice-lagged input in Model 3A ( $\beta_{4}=$ $0.99, p<0.01)$. Thus, the direct effect of twice-lagged cumulative customer input is absorbed entirely by the interaction with project revisions, supporting H3.

Lastly, to test whether distant funding experience of commenting customers significantly moderates the effect of input on funding (H4), we include an interaction term between input and distance in Model 4. The individual effect of customer input is reduced to 0.11 and is not significant anymore, whereas the interaction with distance is $\beta_{3}=13.83$ and significant $(p<0.01)$. Thus, the effect of customer input on funding depends on the distance of the commenting customers.

We conduct a number of additional empirical analyses that support the robustness of the results. First, in addition to customer-based controls for observational learning, we estimate the panel models with dynamic, funding-based controls (Table 6). Specifically, we replace the customer-based variables with the respective funding-based variables cumulative funding $\left(F_{i, t-1}\right)$ (Zhang and Liu 2012, Agrawal et al. 2015) and new funding $\left(\nabla F_{i, t-1}\right)$. Such dynamic panel models may be subject to Nickell bias, which reduces the coefficient of the lagged dependent variable ( $\nabla F_{i, t-1}$ in our case) (Nickell 1981). However, this is only an issue for small sample $T$ (smaller than 15-30 periods), and the bias vanishes as $T \rightarrow \infty$ (Arellano 2003). In our case, with $T=122$ and an assumed correct coefficient of $\beta=0.5$, the bias is approximately $-2.48 \%$ :

$$
-\frac{1+\beta}{T-1}=-0.0124 \text {. }
$$

The estimated coefficient of the lagged dependent variable $\nabla F_{i, t-1}$ in Table 6 is 0.45 . Given robust standard errors of 0.03 , any potential Nickell bias in our large-T sample does not change the significance or order of magnitude of our results. ${ }^{15}$

Generally, the funding-based models yield similar results to the customer-based models. The effect of customer input on funding tends to be weaker (Model 1: $\left.\beta_{1}=0.79, p<0.01\right)$, but not less significant. In a similar manner, the interaction effects are also reduced but remain equally significant (Model 2: $\beta_{2}=3.88, p<0.01$; Model 3B: $\beta_{4}=0.76, p<0.01$; Model 4: $\beta_{3}=11.57, p<0.01$ ). The dynamic funding-based models therefore confirm the results of the models with customer-based controls.

Second, we explicitly take into account potential autocorrelation of the errors. Although we report standard errors that are clustered at the project level and robust to heteroscedasticity and autocorrelation, we also run all models with first-order autoregressive disturbances, and all results hold.

Third, in the previous models we use the number of Facebook shares to control for the word of mouth of a campaign. We can think of Facebook shares as outgoing word of mouth, as they count the number of times 
Table 5. Panel Models with Customer-Based Controls for Observational Learning

\begin{tabular}{|c|c|c|c|c|c|}
\hline Variables & Model 1 & Model 2 & Model 3A & Model 3B & Model 4 \\
\hline Customer input $(t-1)$ & $1.03^{* * *}(0.25)$ & $1.02^{* * *}(0.24)$ & & & $0.11(0.32)$ \\
\hline Customer input $(t-1) \times$ individual creator & & $4.09^{* * *}(1.51)$ & & & \\
\hline New customer input $(t-1)$ & & & $1.24(1.66)$ & $1.09(1.62)$ & \\
\hline Customer input $(t-2)$ & & & $1.02^{* * *}(0.21)$ & $0.16(0.16)$ & \\
\hline New project revision $(t-1)$ & & & & $128.52^{* * *}(8.83)$ & \\
\hline Customer input $(t-2) \times$ new project revision $(t-1)$ & & & & $0.99^{* * *}(0.17)$ & \\
\hline Distant funding experience $(t-1)$ & & & & & $-77.73^{* * *}(21.28)$ \\
\hline $\begin{array}{l}\text { Customer input }(t-1) \times \text { distant funding } \\
\text { experience }(t-1)\end{array}$ & & & & & $13.83^{* * *}(4.69)$ \\
\hline Cumulative customers $(t-1)$ & $0.44^{*}(0.27)$ & $0.13(0.26)$ & $0.44^{*}(0.26)$ & $0.44^{*}(0.26)$ & $-0.09(0.27)$ \\
\hline New customers $(t-1)$ & $28.43^{* * *}(1.90)$ & $28.30^{* * *}(1.90)$ & $28.39^{* * *}(1.84)$ & $28.00^{* * *}(1.86)$ & $28.22^{* * *}(1.86)$ \\
\hline Average funding $(t-1)$ & $-0.29^{* * *}(0.08)$ & $-0.30^{* * *}(0.08)$ & $-0.29^{* * *}(0.08)$ & $-0.29^{* * *}(0.08)$ & $-0.31^{* * *}(0.08)$ \\
\hline Cumulative Facebook shares $(t-1)$ & $-2.53^{*}(1.31)$ & $-2.49 *(1.27)$ & $-2.53^{*}(1.31)$ & $-2.54^{*}(1.32)$ & $-2.34^{*}(1.26)$ \\
\hline Top $50(t-1)$ & $212.00^{* * *}(67.39)$ & $224.88^{* * *}(65.92)$ & $212.20^{* * *}(67.26)$ & $201.45^{* * *}(66.56)$ & $237.34^{* * *}(69.05)$ \\
\hline New posts $(t-1)$ & $83.04^{* * *}(23.01)$ & $78.54^{* * *}(22.67)$ & $82.75^{* * *}(23.45)$ & $82.56^{* * *}(24.19)$ & $80.68^{* * *}(22.74)$ \\
\hline $20 \% \leq$ Funding ratio $<40 \%$ & $44.05(30.82)$ & $46.41(30.10)$ & $44.08(30.81)$ & $45.24(30.83)$ & $42.77(29.32)$ \\
\hline $40 \% \leq$ Funding ratio $<60 \%$ & $137.75^{* *}(61.98)$ & $144.50^{* *}(60.77)$ & $137.81^{* *}(61.97)$ & $138.69^{* *}(62.08)$ & $136.89^{* *}(59.41)$ \\
\hline $60 \% \leq$ Funding ratio $<80 \%$ & $204.12^{* *}(85.30)$ & $215.39^{* *}(83.89)$ & $204.20^{* *}(85.31)$ & $209.65^{* *}(85.25)$ & $208.90^{* *}(82.09)$ \\
\hline $80 \% \leq$ Funding ratio $<100 \%$ & $250.24^{* *}(104.95)$ & $266.19 * *(103.48)$ & $250.32 * *(104.93)$ & $248.83^{* *}(105.27)$ & $257.18^{* *}(101.77)$ \\
\hline $100 \% \leq$ Funding ratio & $108.92(117.94)$ & $134.04(117.47)$ & $109.00(117.94)$ & $102.68(118.51)$ & $122.63(115.15)$ \\
\hline Campaign time & $-0.02(0.87)$ & $0.20(0.93)$ & $-0.01(0.87)$ & $0.53(0.86)$ & $0.04(0.82)$ \\
\hline Campaign time ${ }^{2}$ & $0.02^{* * *}(0.00)$ & $0.02^{* * *}(0.00)$ & $0.02^{* * *}(0.00)$ & $0.01^{* * *}(0.00)$ & $0.02^{* * *}(0.00)$ \\
\hline Project fixed effects & Yes & Yes & Yes & Yes & Yes \\
\hline Week dummies & Yes & Yes & Yes & Yes & Yes \\
\hline Intercept & $167.84^{* *}(71.40)$ & $180.54^{* *}(71.35)$ & $168.83^{* *}(71.64)$ & $198.43^{* * *}(70.30)$ & $232.22^{* * *}(81.20)$ \\
\hline$F$-statistic & 57.75 & 79.45 & 81.26 & 96.89 & 55.86 \\
\hline$R^{2}$ (within) & 0.57 & 0.58 & 0.57 & 0.58 & 0.58 \\
\hline Observations & $1,387,364$ & $1,387,364$ & $1,387,364$ & $1,387,364$ & $1,387,364$ \\
\hline Projects & 21,491 & 21,491 & 21,491 & 21,491 & 21,491 \\
\hline
\end{tabular}

Notes. The dependent variable is new funding since the last period $\left(\nabla F_{i, t}\right)$. Robust standard errors clustered at the project level are in parentheses. ${ }^{*} p<0.10 ;{ }^{* *} p<0.05 ;{ }^{* * *} p<0.01$.

users talk about a project. In addition, we also run models with the number of Facebook likes. We can think of Facebook likes as incoming word of mouth, as they count the number of times people react to a Facebook share. The results of both specifications are very similar, and all results hold.

Lastly, we also run separate models for the following scenarios: (1) We treat all suspended and cancelled projects as failed projects; (2) we exclude all projects that have any missing observations (we already exclude projects with more than 2 days of missing data); and (3) we include customer-funding experience to control explicitly for customer seniority. The results hold in all scenarios. To conclude, the panel models support the results of the IV models.

\section{Discussion}

The study contributes to the growing academic literature on crowdfunding. We depart from the current emphasis on the exchange of financial resources (Kuppuswamy and Bayus 2018) and instead study the nonfinancial impact of customers on crowdfunding projects. We argue that, as in equity-based crowdfunding (in which backers receive shares instead of products), customers' investment in reward-based crowdfunding projects creates a principal-agent relationship between the investing customers as principals and the project creators as agents. In this relationship, customers face agency issues as a result of their dependence on project creators and potentially conflicting objectives (Jensen and Meckling 1976, Hart and Holmström 1987). These issues motivate customer investors to gather information on the project, monitor project progress, and influence product development. We argue that this is beneficial to project creators, as customer involvement substitutes for the support usually received from institutional investors (e.g., angel investors or venture capitalists; Bottazzi et al. 2008). The implication that crowd investors are not a passive source of capital is an important addition to the study of crowds (e.g., Mollick and Nanda 2016). Instead, crowd investors seek to play a more active role in their investments to mitigate the risks of the principal-agent relationship and maximise their expected returns. Understanding crowd investments as principal-agent relationships offers interesting opportunities for future research. For example, are crowd investors better than conventional investors at minimising agency costs?

We also link the elicitation of external information during crowdfunding to the more general concept of 


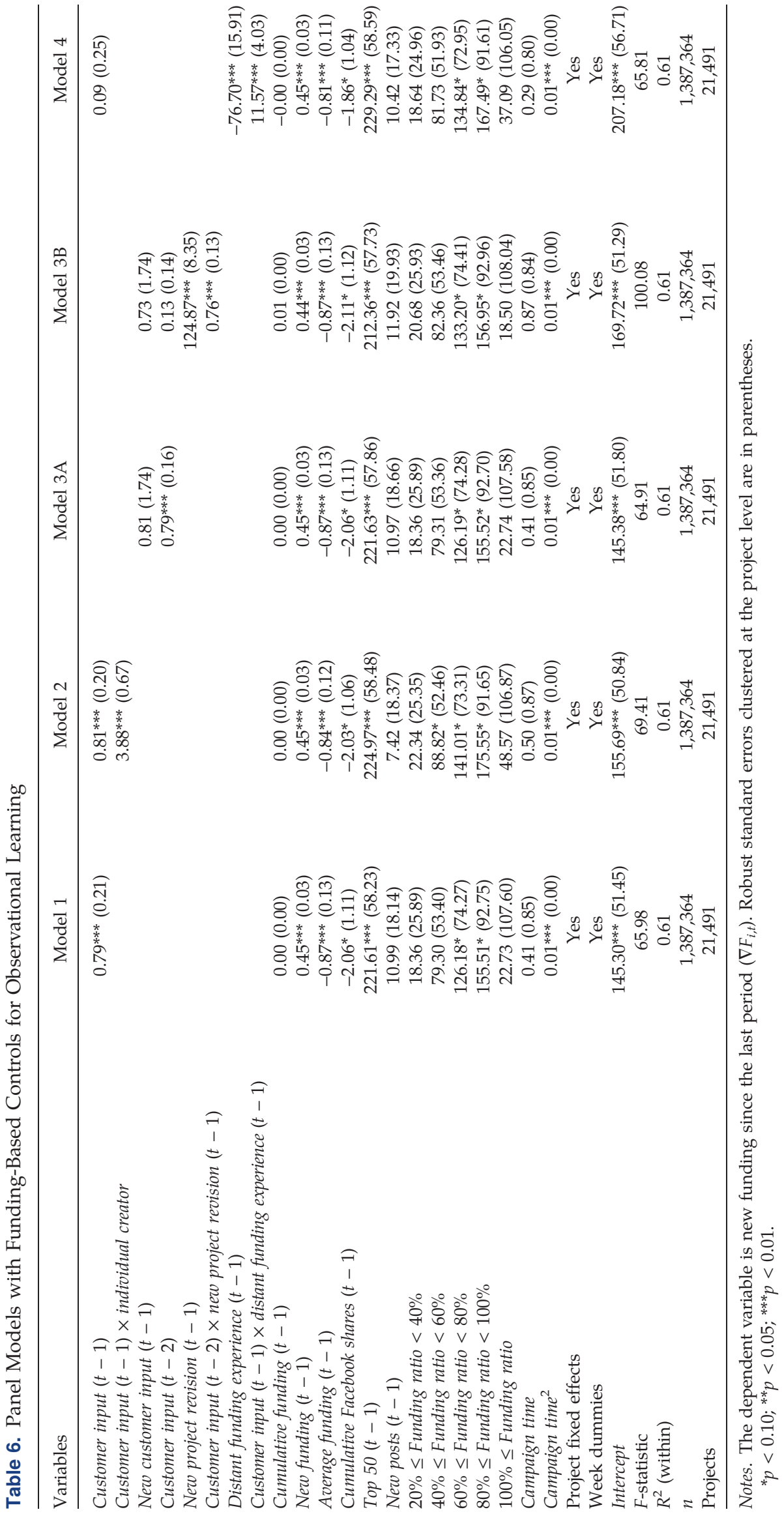


crowdsourcing or crowd-based knowledge sourcing (e.g., Afuah and Tucci 2012, Piezunka and Dahlander 2015). In crowd-based knowledge sourcing, a "problem owner" seeks solutions to a problem from a public crowd of problem solvers. In the case of crowdfunding, the "problem" at hand is the creation of a product that can successfully raise funding. We show that appropriating ideas from the crowd and incorporating these into the product under development increases the product's chances of funding. We also show that, as with crowdsourcing (Afuah and Tucci 2012), distant search increases the value created from crowd input. This is surprising, because the kinds of problems found in crowdfunding differ from those found in crowdsourcing in terms of problem complexity and divisibility into subproblems. We argue that customers' role as principal facilitates distant search for such problems, because it reduces the costs of problem communication and modularisation.

The existing literature on crowd-based knowledge sourcing focuses on two approaches: fixed-problem crowdsourcing (Dell Storm Sessions, Sullivan 2010; the Netflix prize, Afuah and Tucci 2012) and openproblem crowdsourcing (Dell IdeaStorm forum and my Starbucks Idea, Bayus 2013). In fixed-problem crowdsourcing, a problem owner is looking for solutions to a defined problem, such as the most efficient way to predict film rental (Netflix). It can involve contests with monetary rewards (Netflix), and problem solvers may either cooperate (Facebook translations) or compete (Netflix). In open-problem crowdsourcing, an organisation is looking for feedback, often via suggestion boxes, on a wider range of topics (Piezunka and Dahlander 2015), such as Dell's effort to improve its products through continuous customer feedback (Bayus 2013). There is usually no financial reward, and customers participate just to gain acknowledgement for their contribution (Sullivan 2010). The creation and selection of ideas is influenced by an ongoing community process, which involves voting and commenting on others' ideas (Bayus 2013, Dahlander and Piezunka 2014).

The elicitation of information from customer investors in crowdfunding combines fixed- and open-problem crowdsourcing with financial investments from problem solvers: The problem at hand (to create a successful product) is more fixed than an entirely open suggestion box, but solutions can vary widely. Combining crowd judgments with crowd investments may offer interesting research opportunities. For example, Atanasov et al. (2017) recently studied prediction markets versus prediction polls in crowdsourcing. The prices paid by agents in prediction markets resemble investments in unfinished products by backers (Mollick and Nanda 2016). To follow up on these studies and the present paper, one could link the size of individual investments with backers' influence and funding success. Should project creators listen to the backers with the largest or smallest investments?

The disintermediation of producers and consumers is another interesting aspect of crowdfunding. Industrialisation has removed consumers at the end of the value chain ever further from the producers of goods (Priem 2007). The reversal of this trend through crowdfunding and, more generally, the internet can offer interesting research opportunities for organisational researchers. For instance, to what degree does removing intermediaries increase efficiency, and, in contrast, when does it lead to inefficient allocation of resources?

The study has a number of limitations that present opportunities for future research. First, we argue that backers on reward-based crowdfunding platforms are customer investors, who invest in the development of a product that they receive as a return on their investment (Kuppuswamy and Bayus 2018). Unlike in equity-based crowdfunding, reward-seeking backers face agency costs from residual losses in product utility rather than financial losses. This may not always be strictly true-for instance, when families and friends invest in a project, or when an investment is too small to receive a product and the return is negligible (e.g., a souvenir). ${ }^{16}$ However, previous literature has noted the dominant use of reward-based crowdfunding for presales (Fleming and Sorenson 2016). Thus, the majority of backers who receive a product in return for their investment are customer investors. As mentioned above, investigating the influence of customers at different investment levels may be a worthwhile research opportunity.

Second, at present, reward-based crowdfunding is used predominantly by entrepreneurs. Although there are a few projects by larger organisations in the sample, the applicability of the results to such organisations may be limited. However, involving customer investors in entrepreneurial projects can be useful for established organisations, too (Fleming and Sorenson 2016). For instance, the development of a high-risk product can be made contingent on a successful crowdfunding project. In this way, organisations can raise some of the required capital, benefit from free promotion of their product, and reduce the associated risks by listening to customers. Crowdfunding may therefore be a new way of involving customers virtually and financially in new product development projects.

Third, we operationalise project revisions as the number of changes to project descriptions, but we do not measure the extent or content of these changes. An alternative interpretation of the mediation results $(\mathrm{H} 3)$ may be that prospective customers are more likely to invest in a project merely because they see that creators were not ignoring customer suggestions. However, this is not likely in our setting, because neither prospective 
nor existing customers can see whether, to what extent, or for what reasons project descriptions were changed, as they only observe the final version. Yet, this offers an opportunity for future research to track specific customer requests and how they are incorporated into products.

Fourth, the dependent variables are based on funding. Although this is an important measure of success for project creators, it may be interesting to look at the bottom line or other success variables. Surveys are an initial and easy-to-execute way to acquire data on other success metrics, although, ultimately, one would want to link crowdfunding data with, for example, IPO or profit data.

Fifth, we use an instrumental variable to control for potentially confounding factors such as project quality, creator ability, and popularity. We believe that the instrument allows us to report causal results with greater confidence than with a standard cross-sectional estimation, but it is not perfect. For instance, although we provide qualitative evidence that the app does not increase funding, we do not have quantitative data to verify that. Moreover, the effect of the app may be due to a seasonal increase in commenting. We cannot rule out this alternative explanation, because we do not have data on other seasons. However, the commenting trend within the sample only shows significant increases in commenting around the release of the mobile app, supporting the idea that the app increased commenting. In addition, we run several dynamic panel models that explicitly control for constant project characteristics as well as social learning, and all the results hold. Thus, we have shown with two different models and dependent variables that customer input increases crowdfunding success.

The study results in a number of directly applicable guidelines for entrepreneurs wanting to use crowdfunding. First, input from customer investors can improve a project's chances of success-in fact, it can make the difference between funding and failure. It is good to listen to customer investors, because their feedback and support to some degree replaces the help that entrepreneurs usually receive from angel investors or venture capitalists. Second, customer input can be particularly beneficial for individual project creators, but is less beneficial for teams. Third, creators need to change their project descriptions in response to customer input. This is because projects tend to get better as creators incorporate customer input. Fourth, customers who have more experience in categories other than that of the project (e.g., theatre backers who invest in a video games project) give more valuable input. Their feedback might not be as easy to implement, but these customers offer more heterogeneous insights into the market.

\section{Acknowledgments}

The authors thank department editor Lee Fleming, the associate editor, and four anonymous reviewers for guidance and helpful advice throughout the review process. The authors also thank Martin Kilduff and participants of the UCL School of Management reading group, as well as audiences at INFORMS annual meetings, the 2015 Darden \& Cambridge Judge Entrepreneurship and Innovation Conference, and the 2016 Annual Open and User Innovation Conference for their constructive feedback.

\section{Endnotes}

${ }^{1}$ Reward-based crowdfunding is the act of "raising capital from many people through an online platform" in return for rewards (Agrawal et al. 2014, p. 63). Entrepreneurs and organisations who seek funding are called "project creators" and investors are called "backers." Because rewards are often products, backers are customers for these products (Fleming and Sorenson 2016, Kuppuswamy and Bayus 2018). We discuss limitations of this view in Section 6. For an overview of other forms of crowdfunding, see Kuppuswamy and Bayus (2018).

2 "All-or-nothing" means that project creators can only keep the raised money if they reach their minimum funding goal by the end of the funding campaign.

${ }^{3}$ We control for goal and duration in the analyses and discuss their interpretation in more detail in Section 4.2.

${ }^{4}$ We only have a complete set of observations for short projects at the beginning and end of the data collection. As 30 days is the median project duration, we exclude 1 month on either side of the time horizon.

${ }^{5}$ All results hold when we treat suspended and cancelled projects as failed projects.

${ }^{6}$ All results hold when we run the panel models without projects that have any missing days.

${ }^{7}$ All GBP values are converted at the sample period average rate of 1.58474 USD/GBP

${ }^{8}$ Charities or charitable donations are not allowed on Kickstarter (Kickstarter 2015).

${ }^{9}$ There may be interaction outside the comments (e.g., via email or private message), but such interaction should not bias any effect of customer input observed within the comments.

${ }^{10}$ We do not "measure" the content of changes. That is, we do not measure whether creators change researcher-defined product attributes. We only measure whether the sum of their changes mediates the effect of input on funding.

${ }^{11}$ The roll-out of the new payment system is outside the sample period and does not affect the IV.

${ }^{12}$ In this model, the impact of customer input does not change as a result of accumulation, although this may be plausible in a longterm model. Because the observed time frame in the sample is only 32 days on average, we assume the marginal impact of customer input to be constant

${ }^{13}$ The expected increase in likelihood is $e^{\beta}-1$.

${ }^{14} \mathrm{We}$ use nine levels of coarsening based on the anterior distribution of customers: 0 customers, $1-4$ customers ( $10 \%$ percentile), 5-22 customers ( $25 \%$ percentile), $23-66$ customers (median), 66-148 customers (75\% percentile), $149-244$ customers ( $90 \%$ percentile), 245-615 (95\% percentile), 616-1,231 customers (99\% percentile), and 1,232 and more customers. We match projects on a one-to-one basis.

${ }^{15}$ Arellano-Bond type models (which correct for the Nickell bias) cannot feasibly be computed for large-T samples such as ours (Arellano 2003).

${ }^{16}$ There are no charities or charitable causes in the data. 


\section{References}

Afuah A, Tucci CL (2012) Crowdsourcing as a solution to distant search. Acad. Management Rev. 37(3):355-375.

Agrawal A, Catalini C, Goldfarb A (2014) Some simple economics of crowdfunding. Innovation Policy Econom. 14(1):63-97.

Agrawal A, Catalini C, Goldfarb A (2015) Crowdfunding: Geography, social networks, and the timing of investment decisions. J. Econom. Management Strategy 24(2):253-274.

Altman M, Gill J, McDonald MP (2004) Numerical Issues in Statistical Computing for the Social Scientist (John Wiley \& Sons, Hoboken, $\mathrm{NJ})$.

Arellano M (2003) Panel Data Econometrics (Oxford University Press, Oxford, UK).

Atanasov P, Rescober P, Stone E, Swift SA, Servan-Schreiber E, Tetlock P, Ungar L, Mellers B (2017) Distilling the wisdom of crowds: Prediction markets vs. prediction polls. Management Sci. 63(3):691-706.

Bajaj A, Kekre S, Srinivasan K (2004) Managing NPD: Cost and schedule performance in design and manufacturing. Management Sci. 50(4):527-536.

Banerjee AV (1992) A simple model of herd behavior. Quart. J. Econom. 107(3):797-817.

Baron RM, Kenny DA (1986) The moderator-mediator variable distinction in social psychological research: Conceptual, strategic, and statistical considerations. J. Personality Soc. Psych. 51(6): $1173-1182$

Bayus BL (2013) Crowdsourcing new product ideas over time: An analysis of the Dell IdeaStorm community. Management Sci. 59(1):226-244.

Bikhchandani S, Hirshleifer D, Welch I (1992) A theory of fads, fashion, custom, and cultural change as informational cascades. J. Political Econom. 100(5):992-1026.

Bikhchandani S, Hirshleifer D, Welch I (1998) Learning from the behavior of others: Conformity, fads, and informational cascades. J. Econom. Perspect. 12(3):151-170.

Blackwell M, Iacus S, King G, Porro G (2009) CEM: Coarsened exact matching in Stata. Stata J. 9(4):524-546.

Bosch-Rekveldt M, Jongkind Y, Mooi H, Bakker H, Verbraeck A (2011) Grasping project complexity in large engineering projects: The TOE (technical, organizational and environmental) framework. Internat. J. Project Management 29(6):728-739.

Bottazzi L, Da Rin M, Hellmann T (2008) Who are the active investors? Evidence from venture capital. J. Financial Econom. 89(3):488-512.

Boudreau KJ, Lacetera N, Lakhani KR (2011) Incentives and problem uncertainty in innovation contests: An empirical analysis. Management Sci. 57(5):843-863.

Burtch G, Ghose A, Wattal S (2013) An empirical examination of the antecedents and consequences of contribution patterns in crowdfunded markets. Inform. Systems Res. 24(3):499-519.

Burtch G, Ghose A, Wattal S (2015) The hidden cost of accommodating crowdfunder privacy preferences: A randomized field experiment. Management Sci. 61(5):949-962.

Cai H, Chen Y, Fang H (2009) Observational learning: Evidence from a randomized natural field experiment. Amer. Econom. Rev. 99(3): 864-882.

Chatterji AK, Fabrizio K (2011) How do product users influence corporate invention? Organ. Sci. 23(4):971-987.

Colombo MG, Franzoni C, Rossi-Lamastra C (2014) Internal social capital and the attraction of early contributions in crowdfunding. Entrepreneurship Theory Practice 39(1):75-100.

Dahlander L, Piezunka H (2014) Open to suggestions: How organizations elicit suggestions through proactive and reactive attention. Res. Policy 43(5):812-827.

Eisenhardt KM (1989) Agency theory: An assessment and review. Acad. Management Rev. 14(1):57-74.
Fischer E, Reuber AR (2004) Contextual antecedents and consequences of relationships between young firms and distinct types of dominant exchange partners. J. Bus. Venturing 19(5):681-706.

Fleming L, Sorenson O (2016) Financing by and for the masses: An introduction to the special issue on crowdfunding. California Management Rev. 58(2):5-19.

Fontana R, Nuvolari A, Shimizu H, Vezzulli A (2013) Reassessing patent propensity: Evidence from a data set of R\&D awards, 1977-2004. Res. Policy 42(10):1780-1792.

Foss NJ, Laursen K, Pedersen T (2010) Linking customer interaction and innovation: The mediating role of new organizational practices. Organ. Sci. 22(4):980-999.

Godinho de Matos M, Ferreira P, Smith MD (2017) The effect of subscription video-on-demand on piracy: Evidence from a household-level randomized experiment. Management Sci. 64(12):5610-5630.

Gompers PA (1995) Optimal investment, monitoring, and the staging of venture capital. J. Finance 50(5):1461-1489.

Griffin A, Hauser JR (1993) The voice of the customer. Marketing Sci. 12(1):1-27.

Griffin A, Page AL (2003) PDMA success measurement project: recommended measures for product development success and failure. J. Product Innozation Management 13(6):478-496.

Gruner KE, Homburg C (2000) Does customer interaction enhance new product success? J. Bus. Res. 49(1):1-14.

Guevara CA, Ben-Akiva ME (2012) Change of scale and forecasting with the control-function method in logit models. Transportation Sci. 46(3):425-437.

Hall BH, Helmers C, Rogers M, Sena V (2013) The importance (or not) of patents to UK firms. Oxford Econom. Papers 65(3):603-629.

Hart O, Holmström B (1987) The theory of contracts. Bewley TF, ed. Advances in Economic Theory (Cambridge University Press, Cambridge, UK), 71-156.

Hsu DH (2004) What do entrepreneurs pay for venture capital affiliation? J. Finance 59(4):1805-1844.

Iacus SM, King G, Porro G (2019) A theory of statistical inference for matching methods in causal research. Political Anal. Forthcoming.

Iacus SM, King G, Porro G (2012) Causal inference without balance checking: Coarsened exact matching. Political Anal. 20(1):1-24.

Isenberg D (2012) The road to crowdfunding hell. Harvard Bus. Rev. Accessed April 23, 2012, https://hbr.org/2012/04/the-road-to -crowdfunding-hell.

Jensen MC, Meckling WH (1976) Theory of the firm: Managerial behavior, agency costs and ownership structure. J. Financial Econom. 3(4):305-360.

Jeppesen LB, Lakhani KR (2010) Marginality and problem-solving effectiveness in broadcast search. Organ. Sci. 21(5):1016-1033.

Kickstarter (2014a) One question, six creators: What makes a good project page? Kickstarter Blog. Accessed January 28, 2015, https:// www.kickstarter.com/blog/one-question-six-creators-what-makes -a-good-project-page.

Kickstarter (2014b) Terms of use. Accessed January 26, 2015, https:// www.kickstarter.com/terms-of-use.

Kickstarter (2015) Our rules. Accessed February 4, 2015, https:// www.kickstarter.com/rules.

Kickstarter Executive (2014) Personal conversation with Philipp Cornelius, London, October 13.

Kuppuswamy V, Bayus BL (2017) Does my contribution to your crowdfunding project matter? J. Bus. Venturing 32(1):72-89.

Kuppuswamy V, Bayus BL (2018) A review of crowdfunding research and findings. Golder PN, Mitra D, eds. Handbook of New Product Development Research (Edward Elgar Publishing Ltd., Cheltenham Glos, UK), 361-373.

Larsson R, Bowen DE (1989) Organization and customer: Managing design and coordination of services. Acad. Management Rev. 14(2):213-233. 
Levinthal DA (1998) The slow pace of rapid technological change: Gradualism and punctuation in technological change. Indust. Corporate Change 7(2):217-247.

Ley A, Weaven S (2011) Exploring agency dynamics of crowdfunding in start-up capital financing. Acad. Entrepreneurship J. 17(1):85-111.

Lilien GL, Morrison PD, Searls K, Sonnack M, von Hippel E (2002) Performance assessment of the lead user idea-generation process for new product development. Management Sci. 48(8):1042-1059.

Lin M, Viswanathan S (2016) Home bias in online investments: An empirical study of an online crowdfunding market. Management Sci. 62(5):1393-1414.

Liu TX, Yang J, Adamic LA, Chen Y (2014) Crowdsourcing with allpay auctions: A field experiment on Taskcn. Management Sci. 60(8):2020-2037.

Liu X, Lovely ME, Ondrich J (2010) The location decisions of foreign investors in China: Untangling the effect of wages using a control function approach. Rev. Econom. Statist. 92(1):160-166.

Magnusson PR (2009) Exploring the contributions of involving ordinary users in ideation of technology-based services. J. Product Innovation Management 26(5):578-593.

McFadden D (1974) Conditional logit analysis of qualitative choice behavior. Zarembka P, ed. Frontiers in Econometrics (Academic Press, New York), 105-142.

Moe WW, Fader PS (2002) Using advance purchase orders to forecast new product sales. Marketing Sci. 21(3):347-364.

Mollick E (2014) The dynamics of crowdfunding: An exploratory study. J. Bus. Venturing 29(1):1-16.

Mollick E, Nanda R (2016) Wisdom or madness? Comparing crowds with expert evaluation in funding the arts. Management Sci. 62(2): 1533-1553.

Müller R, Turner JR (2007) Matching the project manager's leadership style to project type. Internat. J. Project Management 25(1):21-32.

Nambisan S (2002) Designing virtual customer environments for new product development: Toward a theory. Acad. Management Rev. 27(3):392-413.

Nickell S (1981) Biases in dynamic models with fixed effects. Econometrica 49(6):1417-1426.

Nijssen EJ, Hillebrand B, de Jong JPG, Kemp RGM (2012) Strategic value assessment and explorative learning opportunities with customers. J. Product Innovation Management 29(S1):91-102.

Osadchiy N, Gaur V, Seshadri S (2016) Systematic risk in supply chain networks. Management Sci. 62(6):1755-1777.

Pierce L, Snow DC, McAfee A (2015) Cleaning house: The impact of information technology monitoring on employee theft and productivity. Management Sci. 61(10):2299-2319.
Piezunka H, Dahlander L (2015) Distant search, narrow attention: How crowding alters organizations' filtering of suggestions in crowdsourcing. Acad. Management J. 58(3):856-880.

Pindyck RS, Rubinfeld DL (1991) Econometric Models and Economic Forecasts, 3rd ed. (McGraw-Hill, Singapore).

Priem RL (2007) A consumer perspective on value creation. Acad. Management Rev. 32(1):219-235.

Priem RL, Li S, Carr JC (2012) Insights and new directions from demand-side approaches to technology innovation, Entrepreneurship, and strategic management research. J. Management 38(1):346-374.

Ramdas K, Meyer M, Randall T (2007) Who do I listen to? The role of the customer in product evolution. Loch $\mathrm{CH}$, Kavadias S, eds. Handbook of New Product Development Management (ButterworthHeinemann, Oxford, UK), 345-375.

Singh J, Fleming L (2010) Lone inventors as sources of breakthroughs: Myth or reality? Management Sci. 56(1):41-56.

Smith S, Windmeijer F, Wright E (2015) Peer effects in charitable giving: Evidence from the (running) field. Econom. J. 125(585): 1053-1071.

Strickler Y, Chen P, Adler C (2012) Kickstarter is not a store. Kickstarter Blog. Accessed January 26, 2015, https://www.kickstarter.com/ blog/kickstarter-is-not-a-store.

Sullivan EA (2010) A group effort: More companies are turning to the wisdom of the crowd to find ways to innovate. Marketing News 44(2):22-29.

von Hippel E (1994) "Sticky information" and the locus of problem solving: Implications for innovation. Management Sci. 40(4): 429-439.

von Hippel E (1998) Economics of product development by users: The impact of "sticky" local information. Management Sci. 44(5): 629-644.

West MA, Anderson NR (1996) Innovation in top management teams. J. Appl. Psych. 81(6):680-693.

Wind J, Mahajan V (1997) Issues and opportunities in new product development: An introduction to the special issue. J. Marketing Res. 34(1):1-12.

Wooldridge JM (2010) Econometric Analysis of Cross Section and Panel Data (MIT Press, Cambridge, MA).

Yli-Renko H, Autio E, Sapienza HJ (2001) Social capital, knowledge acquisition, and knowledge exploitation in young technologybased firms. Strategic Management J. 22(6-7):587-613.

Younkin P, Kashkooli K (2016) What problems does crowdfunding solve? California Management Rev. 58(2):20-43.

Zhang J, Liu P (2012) Rational herding in microloan markets. Management Sci. 58(5):892-912. 